\title{
Measurements of greenhouse gases and related tracers at Bialystok tall tower station in Poland
}

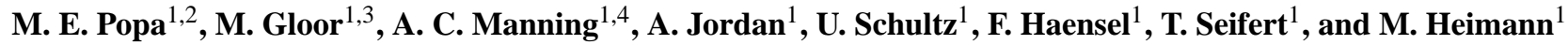 \\ ${ }^{1}$ Max-Planck Institute for Biogeochemistry, Jena, Germany \\ ${ }^{2}$ Energy research Centre of the Netherlands, Petten, The Netherlands \\ ${ }^{3}$ School of Geography, University of Leeds, Leeds, UK \\ ${ }^{4}$ School of Environmental Sciences, University of East Anglia, Norwich, UK
}

Received: 1 August 2009 - Published in Atmos. Meas. Tech. Discuss.: 14 October 2009

Revised: 11 March 2010 - Accepted: 12 March 2010 - Published: 30 March 2010

\begin{abstract}
Quasi-continuous, in-situ measurements of atmospheric $\mathrm{CO}_{2}, \mathrm{O}_{2} / \mathrm{N}_{2}, \mathrm{CH}_{4}, \mathrm{CO}, \mathrm{N}_{2} \mathrm{O}$, and $\mathrm{SF}_{6}$ have been performed since August 2005 at the tall tower station near Bialystok, in Eastern Poland, from five heights up to $300 \mathrm{~m}$. Besides the in-situ measurements, flask samples are filled approximately weekly and measured at Max-Planck Institute for Biogeochemistry for the same species and, in addition, for $\mathrm{H}_{2}, \mathrm{Ar} / \mathrm{N}_{2}$ and the stable isotopes ${ }^{13} \mathrm{C}$ and ${ }^{18} \mathrm{O}$ in $\mathrm{CO}_{2}$. The in-situ measurement system was built based on commercially available analysers: a LiCor 7000 for $\mathrm{CO}_{2}$, a Sable Systems "Oxzilla" FC-2 for $\mathrm{O}_{2}$, and an Agilent 6890 gas chromatograph for $\mathrm{CH}_{4}, \mathrm{CO}, \mathrm{N}_{2} \mathrm{O}$ and $\mathrm{SF}_{6}$. The system was optimized to run continuously with very little maintenance and to fulfill the precision requirements of the CHIOTTO project. The $\mathrm{O}_{2} / \mathrm{N}_{2}$ measurements in particular required special attention in terms of technical setup and quality assurance. The evaluation of the performance after more than three years of operation gave overall satisfactory results, proving that this setup is suitable for long term remote operation with little maintenance. The precision achieved for all species is within or close to the project requirements. The comparison between the in-situ and flask sample results, used to verify the accuracy of the in-situ measurements, showed no significant difference for $\mathrm{CO}_{2}, \mathrm{O}_{2} / \mathrm{N}_{2}, \mathrm{CH}_{4}$ and $\mathrm{N}_{2} \mathrm{O}$, and a very small difference for $\mathrm{SF}_{6}$. The same comparison however revealed a statistically significant difference for $\mathrm{CO}$, of about $6.5 \mathrm{ppb}$, for which the cause could not be fully explained.
\end{abstract}

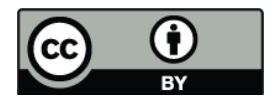

Correspondence to: M. E. Popa (popa@ecn.nl)
From more than three years of data, the main features at Bialystok have been characterized in terms of variability, trends, and seasonal and diurnal variations. $\mathrm{CO}_{2}$ and $\mathrm{O}_{2} / \mathrm{N}_{2}$ show large short term variability, and large diurnal signals during the warm seasons, which attenuate with the increase of sampling height. The trends calculated from this dataset, over the period August 2005 to December 2008, are $2.02 \pm 0.46 \mathrm{ppm} /$ year for $\mathrm{CO}_{2}$ and $-23.2 \pm 2.5 \mathrm{per}$ meg/year for $\mathrm{O}_{2} / \mathrm{N}_{2} . \mathrm{CH}_{4}, \mathrm{CO}$ and $\mathrm{N}_{2} \mathrm{O}$ show also higher variability at the lower sampling levels, which in the case of $\mathrm{CO}$ is strongly seasonal. Diurnal variations in $\mathrm{CH}_{4}, \mathrm{CO}$ and $\mathrm{N}_{2} \mathrm{O}$ mole fractions can be observed during the warm season, due to the periodicity of vertical mixing combined with the diurnal cycle of anthropogenic emissions. We calculated increase rates of $10.1 \pm 4.4 \mathrm{ppb} /$ year for $\mathrm{CH}_{4},(-8.3) \pm 5.3 \mathrm{ppb} /$ year for $\mathrm{CO}$ and $0.67 \pm 0.08 \mathrm{ppb} / \mathrm{year}$ for $\mathrm{N}_{2} \mathrm{O} . \mathrm{SF}_{6}$ shows only few events, and generally no vertical gradients, which suggests that there are no significant local sources. A weak $\mathrm{SF}_{6}$ seasonal cycle has been detected, which most probably is due to the seasonality of atmospheric circulation. $\mathrm{SF}_{6}$ increased during the time of our measurement at an average rate of $0.29 \pm 0.01 \mathrm{ppt} / \mathrm{year}$.

\section{Introduction}

Atmospheric measurements are a tool to quantify greenhouse gas fluxes into and out of the atmosphere, and to understand the underlying processes. Traditionally, most of the atmospheric measurement stations were remotely located. Continental stations were avoided because the large concentration variability in the vicinity of strong sources makes the data difficult to interpret.

Published by Copernicus Publications on behalf of the European Geosciences Union. 
Tans (1991) proposed a strategy to address the need of continental measurements, overcoming the main problems associated with them, by measuring $\mathrm{CO}_{2}$ and other gas species on tall towers. To infer fluxes at regional level, it is useful to sample close to the earth surface (in the planetary boundary layer), where the proximity to sources and sinks results in large signals with high temporal resolution. If the gases are measured at sufficient height above ground (ideally a few hundred meters to avoid local influences), the signal integrates fluxes over a footprint on the order of 500 to $1000 \mathrm{~km}$ around (Gloor et al., 2001). Sampling continuously from different heights above ground allows one to separate the local from regional signals (Gloor et al., 2000).

Following this strategy, in 1992 NOAA-CMDL (now NOAA-ESRL GMD) started a measurement program in North-America using 300-500 m tall towers (Bakwin et al., 1995, 1998). Also in 1992, measurements from a tall tower at Tsukuba, Japan (Inoue and Matsueda, 2001) were started. In Europe tall tower measurements were first brought into operation at Cabauw, Netherlands in 1992 (Vermeulen et al., 1997), Hegyhátsál, Hungary in 1994 (Haszpra et al., 2001), and Norunda, Sweden in 1994 (Lundin et al., 1999).

The need to better determine the distribution of sources and sinks of greenhouse gases became more imperative following the ratification of the Kyoto Protocol. Inverse modeling studies identified the lack of continental stations as a strong limitation in resolving the longitudinal fluxes distribution (Fan et al., 1998; Gloor et al., 2000; Prentice et al., 2000; Schimel et al., 2001).

In this context, the EU-funded project CHIOTTO (Continuous HIgh-precisiOn Tall Tower Observations of Greenhouse Gases in Europe, EVK2-CT-2002-00163) was launched in 2002, with the mission to build a coherent infrastructure for continuous monitoring of greenhouse gas concentrations across Europe above the surface layer (Vermeulen et al., 2004). The approach of the project was to measure continuously the mole fractions of $\mathrm{CO}_{2}$, and other greenhouse gases or species related to the carbon cycle like $\mathrm{CH}_{4}, \mathrm{CO}, \mathrm{N}_{2} \mathrm{O}$ and $\mathrm{SF}_{6}$, at different heights in the boundary layer, using tall towers. The mole fraction data coupled with information about atmospheric transport (inverse modeling technique) are used to obtain regionally representative greenhouse gas flux estimates for Europe. One of the strengths of the CHIOTTO project was to create a harmonized monitoring network, for which partial standardization of the equipment and of the measurement procedures was required. The target precision of the measurements was common for all partners and was established taking into account the WMO recommendations (WMO - GAW 161, 2005). CHIOTTO incorporated the already existing European tall tower stations and added new ones (Haszpra et al., 2001; Thompson et al., 2009). Another tall tower station was set up in Siberia (Kozlova and Manning, 2009), which, although not part of the CHIOTTO network, had many similarities in terms of technical design to the CHIOTTO towers.
MPI-BGC (Max Planck Institute for Biogeochemistry, Jena, Germany) was responsible for setting up two of the CHIOTTO tall tower monitoring stations, one at Ochsenkopf, Germany (Thompson et al., 2009), and one near Bialystok, in Eastern Poland, the subject of this paper. For the new station at Bialystok, an analysis system for quasicontinuous, in-situ measurements of $\mathrm{CO}_{2}, \mathrm{CH}_{4}, \mathrm{CO}, \mathrm{N}_{2} \mathrm{O}$ and $\mathrm{SF}_{6}$ mole fractions and $\mathrm{O}_{2} / \mathrm{N}_{2}$ ratio was designed and built based on commercially available analyzers. The challenge was to obtain a reliable automatic system that can run continuously with very little maintenance, and at the same time fulfil the high precision requirements for all the measured species. The tall tower station Bialystok (BIK) became operational in August 2005, continuing to the present. The system measures air sampled from five heights of the tower, between 5 and $300 \mathrm{~m}$ above ground. The measurement instruments are: an Oxzilla FC-2 $\mathrm{O}_{2}$ fuel cell analyzer, a LiCor 7000 NDIR (non-dispersive infrared) $\mathrm{CO}_{2}$ analyzer and an Agilent 6890 gas chromatograph set up for $\mathrm{CH}_{4}, \mathrm{CO}, \mathrm{N}_{2} \mathrm{O}$ and $\mathrm{SF}_{6}$ analysis.

A comprehensive description of the measurement setup can be found in Popa (2008). In this paper we present the main technical aspects, which can be helpful for interpreting the measurement data and for comparing them with data from other stations. We describe the instrumental setup, the measurement and calibration procedures, and the quality check means employed. We also present the time series of the in-situ measurements during the period 2005-2008, and discuss the typical variability patterns.

Throughout this paper, we use the common units of ppm, $\mathrm{ppb}$, ppt, with the meaning of micro-, nano- and pico-mole per mole of dry air.

\section{Methods}

\subsection{The Bialystok station}

The BIK measurement station was set up at a pre-existing television tower owned by TP EmiTel in Eastern Poland $\left(53^{\circ} 13^{\prime} \mathrm{N}, 23^{\circ} 01^{\prime} \mathrm{E}, 183 \mathrm{~m}\right.$ a.s.l. $)$. The neighbouring area within a few hundreds of kilometres around the tower is flat, with an elevation above sea level of about $150 \mathrm{~m}$. The land is mostly covered by crops and grasslands, with patches of forest and wetlands. The nearest town, Bialystok, with about 300000 inhabitants, is situated about $20 \mathrm{~km} \mathrm{SE}$ of the tower; the metropolitan area of Warsaw lies more than $160 \mathrm{~km} \mathrm{SW}$ of the tower. Excluding Bialystok, the mean population density within a $50 \mathrm{~km}$ radius around the tower is below 60 inhabitants $/ \mathrm{km}^{2}$. Also there is no significant industry in the neighbouring vicinity. According to Henne et al. (2009), BIK is classified as a rural background site.

The climate is continental, with large differences between summer and winter temperatures. The average influence area for the air sampled at Bialystok tower at $300 \mathrm{~m}$ above ground, 
as calculated for the year 2005 using the COMET transport model (Vermeulen et al., 1999), is illustrated in Fig. 1.

\subsection{Measurement setup}

Mole fractions of $\mathrm{CO}_{2}, \mathrm{CH}_{4}, \mathrm{CO}, \mathrm{N}_{2} \mathrm{O}$ and $\mathrm{SF}_{6}$ and the $\mathrm{O}_{2} / \mathrm{N}_{2}$ ratio are measured in-situ, quasi-continuously, meaning a sample point every $3 \mathrm{~min}$ for $\mathrm{CO}_{2}$ and $\mathrm{O}_{2} / \mathrm{N}_{2}$, and every $14 \mathrm{~min}$ for the GC species. The main part of the measurement system is installed at the base of the tower, inside a thermally controlled laboratory container $\left( \pm 2{ }^{\circ} \mathrm{C}\right)$. There are two almost independent modules; one of them measures $\mathrm{CO}_{2}$ mole fraction and $\mathrm{O}_{2} / \mathrm{N}_{2}$ ratio, and the other measures the mole fractions of $\mathrm{CH}_{4}, \mathrm{CO}, \mathrm{N}_{2} \mathrm{O}$ and $\mathrm{SF}_{6}$ by a gas chromatographic method. The connection between the two modules consists in sharing some of the calibration gases, which requires partial coordination.

The system is designed to measure alternately air sampled from five heights of the tower: 5, 30, 90, 180 and $300 \mathrm{~m}$. The air inlets are fixed on the tower at these heights, and atmospheric air is collected continuously by pumps installed inside the measurement container. From each sampling height, there are dedicated inlet lines (12 mm outside diameter Synflex 1300 tubing) for each of the two measurement modules. Only one sampling height is selected at a time, independently for each of the two measurement systems, but the air flow is continuously maintained through all the lines. The air from the selected height is cryogenically dried to a dewpoint of about $-80^{\circ} \mathrm{C}$, before being directed to the gas analysers.

\subsection{1 $\mathrm{CO}_{2}$ and $\mathrm{O}_{2} / \mathrm{N}_{2}$ measurement}

The $\mathrm{CO}_{2}$ and $\mathrm{O}_{2} / \mathrm{N}_{2}$ measurement system has been developed having as starting point the technique introduced by Stephens et al. (2001, 2007) and the further experience achieved from the first setup of the tall tower station at Ochsenkopf, Germany. The gas flow diagram of the $\mathrm{CO}_{2}$ and $\mathrm{O}_{2} / \mathrm{N}_{2}$ measurement system is shown in Fig. 2. $\mathrm{CO}_{2}$ and $\mathrm{O}_{2}$ mole fractions are measured successively from the same air sample with a LiCor 7000 non-dispersive infrared (NDIR) $\mathrm{CO}_{2}$ analyzer and an Oxzilla FC-2 (Sable Systems) $\mathrm{O}_{2}$ fuel cell analyzer.

A peculiarity of atmospheric oxygen measurements is that the results are reported as $\mathrm{O}_{2} / \mathrm{N}_{2}$ ratio and not as mole fraction, because the $\mathrm{O}_{2}$ mole fraction will be significantly influenced by variations in other species (notably $\mathrm{CO}_{2}$ ), possibly leading to erroneous conclusions about $\mathrm{O}_{2}$ fluxes. $\mathrm{O}_{2} / \mathrm{N}_{2}$ variations, in contrast, reflect better the fluxes of $\mathrm{O}_{2}$ in and out of the atmosphere (Keeling and Shertz, 1992). The variations in $\mathrm{O}_{2} / \mathrm{N}_{2}$ are expressed in "per meg", a relative unit defined by comparison with an arbitrary reference (Manning and Keeling, 2006):

$\delta \mathrm{O}_{2} / \mathrm{N}_{2}($ permeg $)=\left(\frac{\left(\mathrm{O}_{2} / \mathrm{N}_{2}\right)_{\text {sample }}}{\left(\mathrm{O}_{2} / \mathrm{N}_{2}\right)_{\text {reference }}}-1\right) \times 10^{6}$

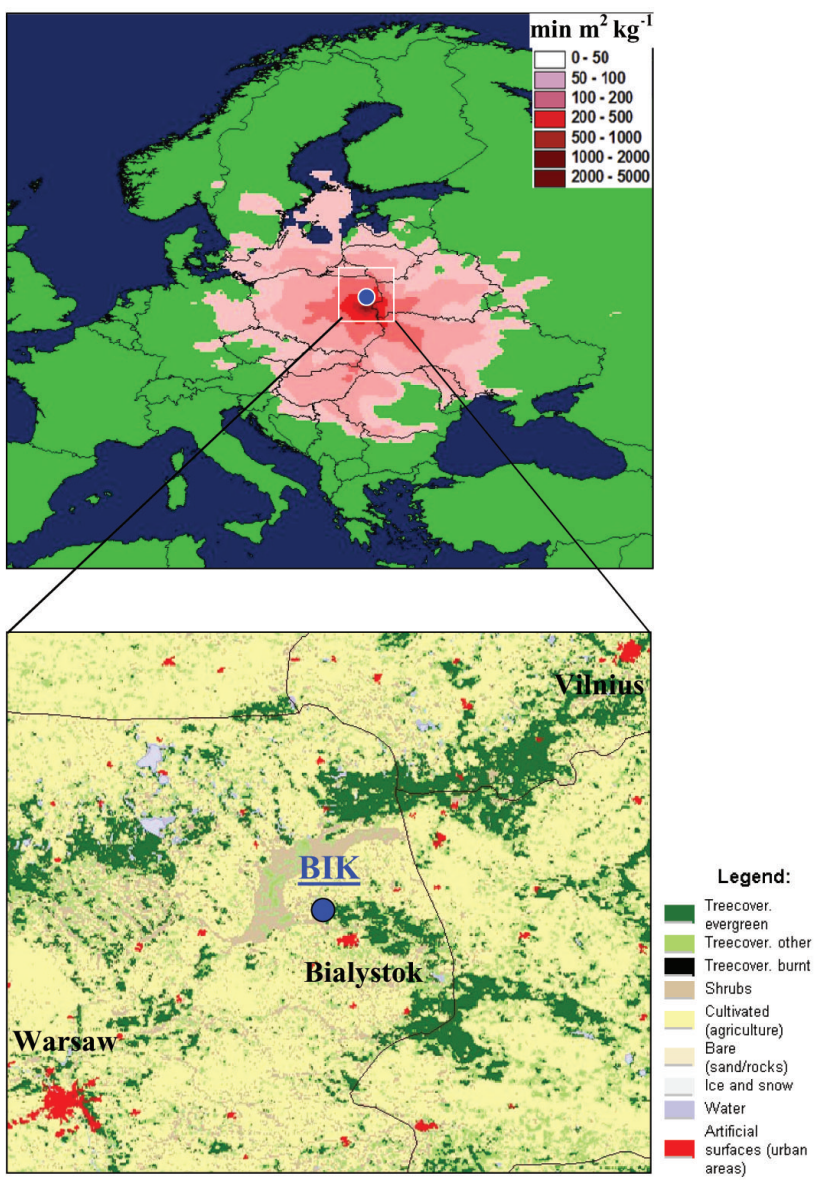

Fig. 1. a) Footprint area of the Bialystok tall tower station (level $300 \mathrm{~m}$ a.g.1.), for the year 2005, estimated for $\mathrm{CO}_{2}$ with the COMET model (figure courtesy A. Vermeulen, ECN Netherlands). The units are relative to a total of $10^{6}$ and signify the relative contribution of unit of flux to the mole fraction variation (in ppm) observed at Bialystok; b) Land cover in the surroundings of the station. Map from Globalis.gvu.unu.edu (data source: GLC2000 - European Commission, Joint Research Centre, 2003).

In our setup, the $\mathrm{O}_{2} / \mathrm{N}_{2}$ ratio is calculated using the measured $\mathrm{O}_{2}$ mole fraction, and corrected for the $\mathrm{CO}_{2}$ dilution effect using measured $\mathrm{CO}_{2}$, according to the following formula:

$\delta \mathrm{O}_{2} / \mathrm{N}_{2}($ per meg $)=\frac{\Delta X_{\mathrm{O} 2}(\mathrm{ppm})+\left(\mathrm{CO}_{2}-\mathrm{CO}_{2 \mathrm{ref}}\right) \times X_{\mathrm{O} 2}^{0}}{X_{\mathrm{O} 2}^{0} \times\left(1-X_{\mathrm{O} 2}^{0}\right)}$

where $\Delta X_{\mathrm{O} 2}(\mathrm{ppm})$ is the measured $\mathrm{O}_{2}$ mole fraction, relative to a scale specific reference; $X_{\mathrm{O} 2}^{0}=0.20946$ (reference mole fraction of $\mathrm{O}_{2}$ in air); $\mathrm{CO}_{2 \mathrm{ref}}=363.29 \mathrm{ppm}$ (specific to SIO scale).

The measurement for both $\mathrm{CO}_{2}$ and $\mathrm{O}_{2}$ is differential, which means that the sample is measured in parallel with a reference gas from a high pressure cylinder ("Working tank") and the difference between the sample and the reference is used to compute the mole fractions. The sample and reference lines are maintained at the same pressure by 


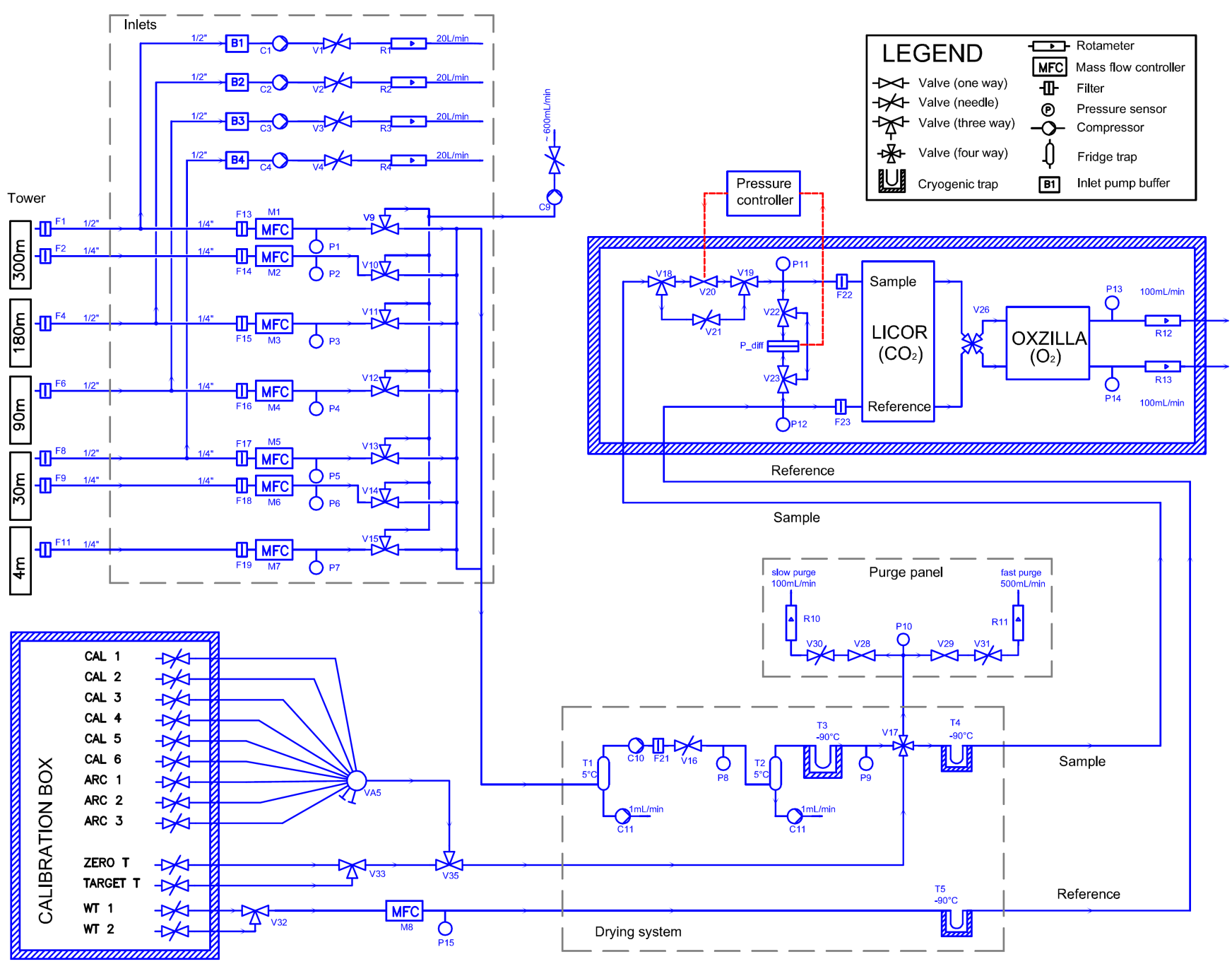

Fig. 2. Flow diagram of the $\mathrm{CO}_{2}$ and $\mathrm{O}_{2} / \mathrm{N}_{2}$ measurement system.

a differential pressure controller (MKS 250E) coupled with a differential pressure sensor (MKS 223BD) and a solenoid valve (MKS 248A). The $\mathrm{O}_{2}$ and $\mathrm{CO}_{2}$ analyzers are installed inside a thermostated chamber $\left( \pm 0.1^{\circ} \mathrm{C}\right)$ to avoid temperature variations influencing the measurement.

A routine calibration takes place every $40 \mathrm{~h}$ using air from a set of four high pressure cylinders with mole fractions spanning the atmospheric range. The values for the calibration gases were assigned by MPI-BGC laboratories, and are traceable to the NOAA-ESRL GMD X2005 scale for $\mathrm{CO}_{2}$ and to the Scripps Institution of Oceanography (SIO) scale for $\mathrm{O}_{2} / \mathrm{N}_{2}$. Only for $\mathrm{CO}_{2}$, there is a more frequent "Zero" calibration, which corrects for possible short term drifts in the baseline response. The name of this gas does not mean that it has zero $\mathrm{CO}_{2}$ mole fraction (actually the Zero calibration gas has a $\mathrm{CO}_{2}$ mole fraction in the normal atmospheric range), but that it is being used to correct the zero term of the analyser's response function (in our case, a quadratic fit).
Gas from a "Target" cylinder is analyzed every few hours to check the stability of the system. The "Target gas" is dry air with concentrations of trace gases in the normal atmospheric range. All high pressure air cylinders used are Luxfer type P2806Z, made from Aluminium alloy, with a volume of $50 \mathrm{~L}$. We use cylinder valves Rotarex- Ceodeux type D20030163 (brass, PCTFE seat) and cylinder pressure regulators Scott Specialty Gases type 51-14C (high purity, two stages, Niplated brass, SS diaphragm).

The system measures alternately air from different sampling lines, and gas from the Target and Zero cylinders, according to predefined sequences. One data point is obtained every $3 \mathrm{~min}$. A certain air or gas line selected is measured 5-6 times in a row. A measurement series of the same gas takes thus $15-18$ min, after which the system switches to the next programmed line. Typically the time interval between two consecutive measurement series of air from the same sampling height varies between $1 \mathrm{~h}$ and $3 \mathrm{~h}$. During 
Table 1. GC measurement specifications.

\begin{tabular}{lll}
\hline & $\mathrm{CH}_{4}$ and $\mathrm{CO}$ & $\mathrm{N}_{2} \mathrm{O}$ and $\mathrm{SF}_{6}$ \\
\hline $\begin{array}{l}\text { Detector type and } \\
\text { characteristics }\end{array}$ & $\mathrm{FID}, 175^{\circ} \mathrm{C}$ & $\mathrm{ECD}, 385^{\circ} \mathrm{C}$ \\
& $\begin{array}{l}\mathrm{Ni} \text { catalyst, } 385{ }^{\circ} \mathrm{C} \\
\mathrm{H}_{2} \text { flow } 50 \mathrm{ml} / \mathrm{min}\end{array}$ & \\
Air flow $320 \mathrm{ml} / \mathrm{min}$ & \\
Oven temperature & $60^{\circ} \mathrm{C}$ & $76^{\circ} \mathrm{C}$ \\
Sample loop volume & $15 \mathrm{ml}$ & $25 \mathrm{ml}$ \\
Precolumn & $\mathrm{SS}, 4 \mathrm{ft}, 1 / 8^{\prime \prime}$ O.D., & $\mathrm{SS}, 6 \mathrm{ft}, 3 / 16^{\prime \prime}$ O.D., \\
& Molsieve 5A, 80-100 mesh & Hayesep Q, 80-100 mesh \\
Column & $\mathrm{SS}, 4 \mathrm{ft}, 1 / 8^{\prime \prime} \mathrm{O} . \mathrm{D} .$, & $\mathrm{SS}, 12 \mathrm{ft}, 3 / 16^{\prime \prime} \mathrm{O} . \mathrm{D} .$, \\
& Unibeads $1 \mathrm{~S}, 60-80$ mesh & Hayesep Q, 80-100 mesh \\
Carrier gas & $\mathrm{N}_{2}$ & P5 (5\% CH in Ar) \\
Run time & 7 min & 7 min \\
\hline
\end{tabular}

the calibration sequence, each calibration gas is measured 12 times $(36 \mathrm{~min})$ and the first 6 measurements are discarded. The full calibration sequence takes $2.4 \mathrm{~h}$.

$\mathrm{O}_{2}$ measurements are particularly sensitive because the $\mathrm{O}_{2}$ content can be altered inside the measurement system by various fractionation phenomena (Keeling et al., 1998a, 2007; Manning, 2001; Sturm et al., 2006). For example, $\mathrm{O}_{2}$ tends to accumulate relative to $\mathrm{N}_{2}$ in regions with lower temperature, higher humidity or higher pressure. The measurement strategy had therefore to be adapted to minimize $\mathrm{O}_{2}$ fractionation effects and to make possible their monitoring. For example, the calibration cylinders are stored horizontally inside a thermally insulated box, in order to minimise gravimetric and thermal $\mathrm{O}_{2}$ fractionation phenomena inside the cylinders. The pressure, flow and temperature gradients which cannot be avoided are maintained as much as possible stationary in time. No plastic is used within the gas flow paths where it can present a significant permeation leak path (i.e. where it would be the only barrier between the sample air and the outside world), because the $\mathrm{O}_{2} / \mathrm{N}_{2}$ ratio could change due to differential permeation. In order to monitor possible fractionation inside the tee-junctions of the main sampling lines (Manning, 2001), additional "control" sampling lines without tee-junctions have been installed at two heights of the tower $(30 \mathrm{~m}$ and $300 \mathrm{~m})$ for comparison with the main sampling lines.

\subsubsection{Gas chromatographic measurement}

The gas chromatographic measurement of $\mathrm{CH}_{4}, \mathrm{CO}, \mathrm{N}_{2} \mathrm{O}$ and $\mathrm{SF}_{6}$ has as starting point the method implemented by Worthy et al. (2003) at the Canadian baseline stations, and the initial setup of the measurement at Ochsenkopf tall tower station (Jordan et al., 2005). $\mathrm{CH}_{4}$ and $\mathrm{CO}$ mole fractions are measured with an Agilent 6890 gas chromatograph equipped with a flame ionization detector (FID) and a $\mathrm{Ni}$ catalyst methanizer, using Molsieve-5A and Unibeads-1S packed columns. The same chromatograph is equipped with an electron capture detector (ECD) and Hayesep Q columns for the analysis of $\mathrm{N}_{2} \mathrm{O}$ and $\mathrm{SF}_{6}$. The scheme of the gas chromatograph is shown in Fig. 3, and Table 1 lists the main parameters of the setup. Appendix A contains a detailed description of the chromatographic method, allowing to reproduce the measurement.

The sample air is measured alternately with a reference gas from a high pressure cylinder, and the ratio between the sample peak and the bracketing reference peaks is used to compute the sample mole fraction. This procedure corrects most of the sensitivity variations on time scales longer than a few minutes. The best precision for mole fraction calculations in the case of $\mathrm{CH}_{4}$ and $\mathrm{N}_{2} \mathrm{O}$ is obtained when using the peak area, whilst for $\mathrm{CO}$ and $\mathrm{SF}_{6}$ the calculation using the peak height leads to better results (Popa, 2008).

A calibration takes place every five days using air from a set of four high pressure cylinders covering the atmospheric range, and gas from a Target cylinder is analyzed every few hours to check the stability. The values for the calibration gases were assigned by MPI-BGC laboratories, and are traceable to internationally recognized scales maintained by NOAA/ESRL GMD. The gas cylinders, cylinder valves and cylinder pressure regulators are the same types as the ones used for the $\mathrm{CO}_{2}$ and $\mathrm{O}_{2} / \mathrm{N}_{2}$ measurements.

The support gases used are as follows. $\mathrm{H}_{2}$ (for the FID flame) is supplied from a high pressure cylinder (purity $99.999 \%$ ) and is purified using Molsieve 13X. Zero air (for the FID flame) is produced by a Parker 75-83 zero air generator, and purified using a self-made purifier containing Molsieve 13X and Sofnocat. $\mathrm{N}_{2}$ (carrier gas for the FID) is produced by a Parker UHP 76-94 generator, and purified by a NuPure ${ }^{\circledR}$ Eliminator ${ }^{\circledR}$ CG purifier (00040-CG-VR4-PF). The carrier gas used for the ECD is a mixture of $5 \% \mathrm{CH}_{4}$ in Ar. This gas is supplied from a high pressure cylinder (ECD quality) and purified by a NuPure ${ }^{\circledR}$ Eliminator ${ }^{\circledR}$ CA purifier (00040-CA-VR4-PF). 


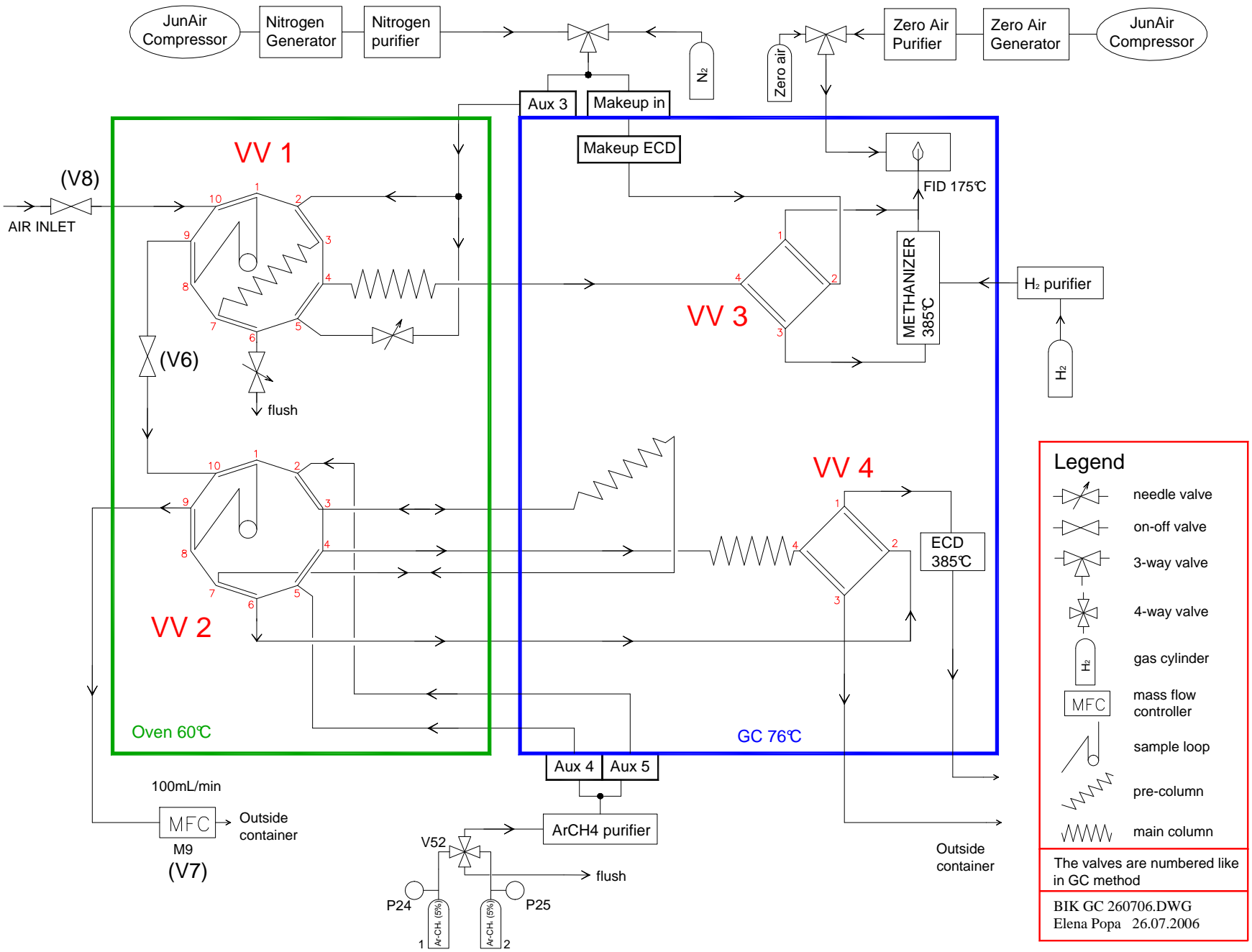

Fig. 3. The GC system diagram - LOAD position.

The system measures alternately air from different sampling lines, and gas from the Target cylinder, according to predefined sequences. One data point is obtained every 14 min. A certain air or gas line selected is measured 3 times in a row. A measurement series of the same gas takes thus $42 \mathrm{~min}$, after which the system switches to the next programmed line. Typically the time interval between two consecutive measurement series of air from the same sampling height is $4-5 \mathrm{~h}$. During the calibration sequence, each calibration gas is measured 6 times $(84 \mathrm{~min})$; the calibration sequence takes $5.6 \mathrm{~h}$.

\subsubsection{Meteorological measurement}

Meteorological parameters are measured at different levels on the tower and the data are transmitted to the main Labview ${ }^{\mathrm{TM}}$ program (see below) by a CAN-Bus system. The meteorological data are registered in the data files every $90 \mathrm{~s}$, together with the $\mathrm{CO}_{2}$ and $\mathrm{O}_{2} / \mathrm{N}_{2}$ data. The measured parameters are:

- wind speed and direction at $75 \mathrm{~m}, 300 \mathrm{~m}$

- atmospheric pressure at $30 \mathrm{~m}, 300 \mathrm{~m}$

- atmospheric temperature at $5 \mathrm{~m}, 30 \mathrm{~m}, 90 \mathrm{~m}, 180 \mathrm{~m}$, $300 \mathrm{~m}$

- atmospheric humidity at $30 \mathrm{~m}, 300 \mathrm{~m}$

\subsubsection{Software}

The measurement system operates unassisted, controlled by a custom written Labview ${ }^{\text {TM }}$ program. The program controls the valve switching according to the preset measurement sequence, acquires data from the analysers and the system diagnostic parameters (flows, pressures, temperatures), and calculates in real time the $\mathrm{CO}_{2}$ mole fraction and $\mathrm{O}_{2} / \mathrm{N}_{2}$ ratio. The Labview ${ }^{\mathrm{TM}}$ program also performs a first level 
quality check and writes the measurement result files. The gas chromatograph has its own software (Agilent Chemstation) which controls the measurement according to the predefined method, and computes the area and height of the peaks. The reports created by Chemstation are read into the Labview ${ }^{\mathrm{TM}}$ software which computes the final calibrated mole fraction results. A computer connection made by Symantec pcAnywhere ${ }^{\text {TM }}$ software via ISDN allows remote control of the system and data transfer to MPI-BGC.

\subsubsection{Flask sampling}

Besides the quasi-continuous measurement, flask samples are filled regularly and sent for analysis at the MPI-BGC laboratory. This provides the possibility to measure additional species $\left(\mathrm{H}_{2}, \mathrm{Ar} / \mathrm{N}_{2} ;{ }^{18} \mathrm{O}\right.$ and ${ }^{13} \mathrm{C}$ in $\left.\mathrm{CO}_{2}\right)$, and constitutes at the same time an important means for quality checking the in-situ measurement. The automated flask sampling apparatus (National Institute of Water \& Atmospheric Research, New Zealand) is fully independent from the main insitu measurement system. Air is sampled via dedicated air inlet lines (12 mm Synflex 1300 tubing) from 30 and $300 \mathrm{~m}$, and dried cryogenically to a dewpoint of about $-80^{\circ} \mathrm{C}$. We use $1 \mathrm{~L}$ glass flasks equipped with two PCTFE sealed valves (Normag, Ilmenau, Germany), preconditioned with dried air at 1.8 bar in MPI-BGC laboratory. The flasks are filled in pairs, to an absolute pressure of 1.6-1.8 bar. Regular sampling takes place about once per week, at 15:00 local time, from the $300 \mathrm{~m}$ height. Samples from the $30 \mathrm{~m}$ height are only filled during special events.

\subsubsection{Quality check means}

A series of quality check means have been implemented for both real-time monitoring and posterior processing. First, a large number of system parameters are recorded every $90 \mathrm{~s}$, together with the raw analyzers' data: the signals from 55 pressure sensors, 5 temperature sensors and 2 flow sensors, additional diagnostic information from analysers, and the status of the electronic valves. These parameters are used by the Labview ${ }^{\mathrm{TM}}$ software to take decisions for the real-time calibration, and used further for the final quality check.

The Target gas measurements are used to signal possible problems and to evaluate the long term performance of the measurement system in terms of precision and stability. The estimation of analytical precision based on the Target gas measurements is presented in Sect. 3.1.2. Intercomparisons using flask samples analysed at MPI-BGC and analyses from "round-robin" high pressure cylinders are used to monitor measurement accuracy; some results of these intercomparisons are presented in Sect. 3.1.3.

There are other means to check specific issues as follows. (i) Air sampled via the "control" lines (see Sect. 2.2.1) is measured every few hours and the results are compared with the ones corresponding to the main sampling lines from the
Table 2. Average precision of the measurement at Bialystok station, and the precision goals of CHIOTTO project.

\begin{tabular}{lll}
\hline Species & $\begin{array}{l}\text { BIK average } \\
\text { reproducibility (stdev) }\end{array}$ & $\begin{array}{l}\text { CHIOTTO } \\
\text { precision goal }\end{array}$ \\
\hline $\mathrm{CO}_{2}$ & $0.08 \mathrm{ppm}$ & $0.05 \mathrm{ppm}$ \\
$\mathrm{O}_{2} / \mathrm{N}_{2}$ & 4.8 per meg & 5 per meg \\
$\mathrm{CH}_{4}$ & $1.7 \mathrm{ppb}$ & $2 \mathrm{ppb}$ \\
$\mathrm{CO}$ & $0.9 \mathrm{ppb}$ & $1 \mathrm{ppb}$ \\
$\mathrm{N}_{2} \mathrm{O}$ & $0.2 \mathrm{ppb}$ & $0.1 \mathrm{ppb}$ \\
$\mathrm{SF}_{6}$ & $0.03 \mathrm{ppt}$ & $0.1 \mathrm{ppt}$ \\
\hline
\end{tabular}

same heights. This comparison has a double purpose: it may indicate an eventual problem (e.g. a broken sampling tubing) and it is a way to detect eventual $\mathrm{O}_{2}$ fractionation. (ii) The measurement from each sampling height or gas cylinder is performed a few times in succession, in order to detect incomplete flushing of the common gas paths. (iii) The Working tank mole fractions of $\mathrm{O}_{2}$, computed after every calibration, are monitored in order to detect eventual evolution of $\mathrm{O}_{2}$ inside cylinders.

\section{Results and discussion}

\subsection{Data coverage and quality}

\subsubsection{Data coverage}

The in-situ measurements of $\mathrm{CO}_{2}, \mathrm{O}_{2} / \mathrm{N}_{2}, \mathrm{CH}_{4}, \mathrm{CO}, \mathrm{N}_{2} \mathrm{O}$ and $\mathrm{SF}_{6}$ were started in August 2005 and they have continued to the present, with two gaps (of about one month each) in 2006 due to technical problems. Between March and November 2008, the $\mathrm{CH}_{4}$ measurements from all sampling levels except for the $5 \mathrm{~m}$ one were affected by a presumed leak in the system and were flagged during post-processing as "bad". The $\mathrm{O}_{2} / \mathrm{N}_{2}$ data between June and November 2008 show large noise due to an instrumental problem; they were not eliminated during the quality check but their potential use is limited by the large noise. The flask sampling was started in November 2005 and had one major interruption of about four months during the summer of 2008.

\subsubsection{Precision}

The long term reproducibility of the Target gas measurement is used as a quantitative estimator of the average analytical precision. Table 2 summarizes the standard deviations of the Target gas measurements, computed for each species using all measurements performed during the whole measurement interval 2005-2008. For $\mathrm{O}_{2} / \mathrm{N}_{2}$, the average precision was estimated excluding the time interval between June and November 2008. The average precisions at Bialystok are comparable with the precision goals of the CHIOTTO project. 

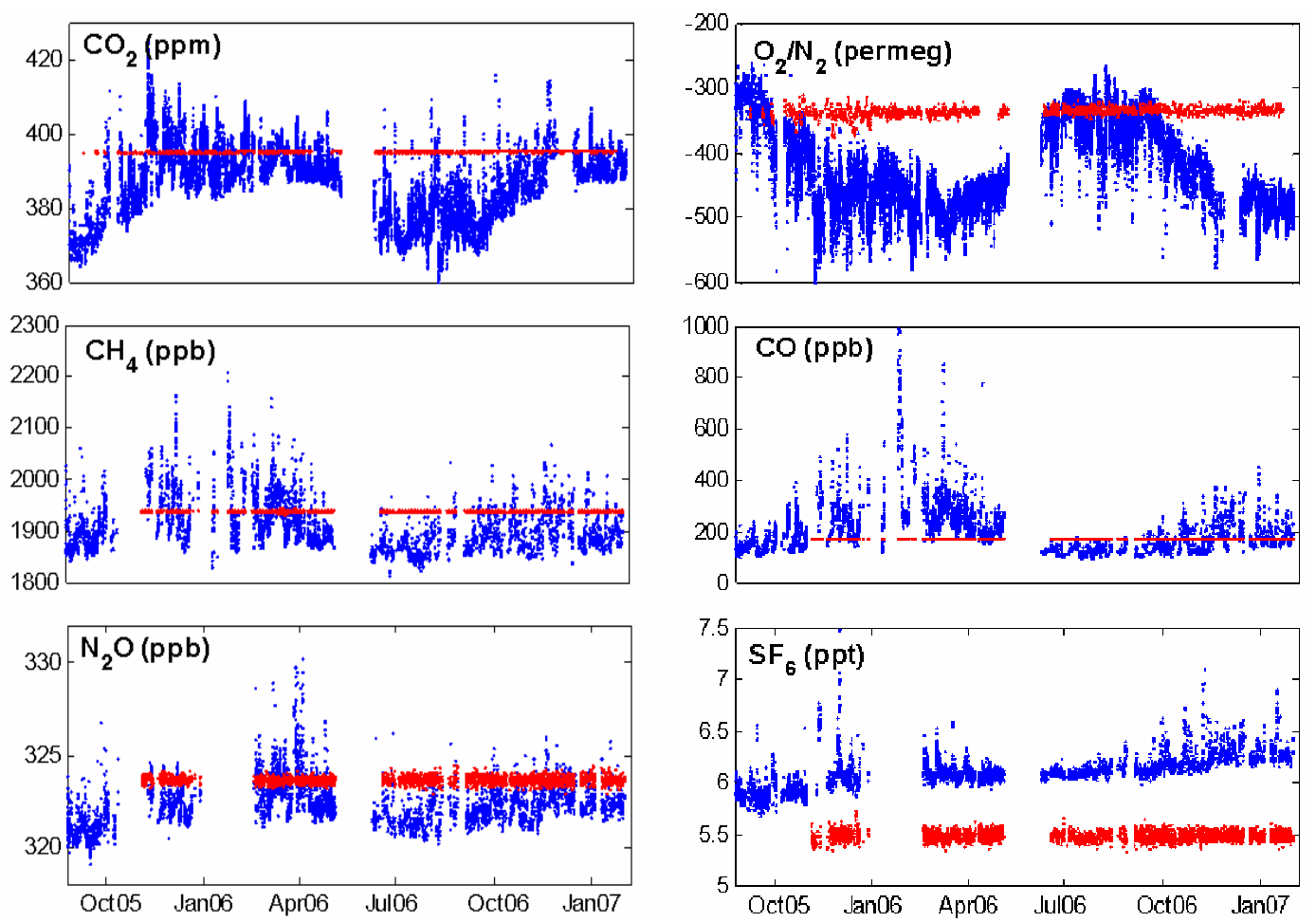

Fig. 4. Comparison between the noise of the Target gas measurement (red) and the atmospheric variability at $300 \mathrm{~m}$ above ground (blue). In order to use the same y-scale for both air and Target gas results, the values of $\mathrm{O}_{2} / \mathrm{N}_{2}$ Target gas measurement have been adjusted with -200 per meg and the values of $\mathrm{SF}_{6}$ Target gas measurement with $-6 \mathrm{ppt}$.

The measurement precision compared with the typical signal amplitude, which can be considered as a signal to noise ratio, can be more suggestive than the absolute value of precision. This is illustrated in Fig. 4, where we compare the measurement of air from the sampling height having the lowest natural variability $(300 \mathrm{~m})$ with the measurement of the Target gas. In the case of $\mathrm{CO}_{2}, \mathrm{CH}_{4}$ and $\mathrm{CO}$, the variability of the Target gas measurement is insignificant compared to the atmospheric short term signals. For $\mathrm{N}_{2} \mathrm{O}$ and $\mathrm{SF}_{6}$, the variability of the Target gas measurement and the atmospheric signals are on the same order of magnitude most of the time, because the atmospheric variability is relatively small. This suggests that an improved analytical precision for these two species would be useful at this specific measurement location, if we want to distinguish better the short term signals.

\subsubsection{Comparisons between in-situ measurement and flask samples}

The comparison of in-situ measurements with flask samples filled at the same location and analyzed at the MPI-BGC laboratory is a valuable tool to estimate the accuracy of the insitu measurement. Because the flask sampling is not synchronized with the in-situ measurement, a direct quantitative comparison of discrete results is not appropriate. Therefore a statistical approach, using a large number of samples, is necessary.
The comparison procedure employed was as follows. Only those flasks were selected for which the nearest in-situ measurement sampling time from $300 \mathrm{~m}$ height was different by at most $2 \mathrm{~h}$ (for $\mathrm{CO}_{2}$ and $\mathrm{O}_{2} / \mathrm{N}_{2}$ ) or $3 \mathrm{~h}$ (for $\mathrm{CH}_{4}, \mathrm{CO}$, $\mathrm{N}_{2} \mathrm{O}$ and $\mathrm{SF}_{6}$ ). Corresponding in-situ values were obtained by linear interpolation at the flask collection times, and the differences were computed between these interpolated values and the flask sample results. For each species, a t-test was performed to check if the average difference is significantly different from zero at a confidence level of $95 \%$.

Table 3 shows for each species the mean difference between in-situ and flask results and its $95 \%$ confidence intervals ("CI 95\%"), the standard error of the mean differences, and the result of the t-test. The standard error of the mean difference ("Difference error" in Table 3) was calculated as the standard deviation of the differences, divided by the square root of the number of flasks. The intervals for a $95 \%$ confidence level are given by the standard error of the mean multiplied by 1.96 .

For $\mathrm{CO}_{2}, \mathrm{O}_{2} / \mathrm{N}_{2}, \mathrm{CH}_{4}$ and $\mathrm{N}_{2} \mathrm{O}$, the mean differences between the in-situ and flask results were not statistically significant. The $\mathrm{CH}_{4}$ difference of $0.82 \mathrm{ppb}$ is however consistent with the results of intercomparisons of high pressure cylinder measurements, within the CarboEurope "Cucumber" programme. The average difference between the cylinder measurements made at BIK (analyses in 2007 and 2008) 
Table 3. Results of the comparison between in-situ and flask sample results. Differences are in-situ minus flasks.

\begin{tabular}{lrrrrr}
\hline Species (unit) & $\begin{array}{r}\text { No. } \\
\text { flasks }\end{array}$ & $\begin{array}{r}\text { Mean } \\
\text { difference BIK-MPI }\end{array}$ & $\begin{array}{r}\text { Difference } \\
\text { error }\end{array}$ & CI 95\% & $\begin{array}{r}\text { t-test } \\
\text { results }\end{array}$ \\
\hline $\mathrm{CO}_{2}(\mathrm{ppm})$ & 211 & 0.02 & 0.06 & $-0.09 \ldots 0.13$ & 0 \\
$\mathrm{O}_{2} / \mathrm{N}_{2}(\mathrm{per}$ meg) & 154 & 1.59 & 1.52 & $-1.41 \ldots 4.60$ & 0 \\
$\mathrm{CH}_{4}(\mathrm{ppb})$ & 148 & 0.82 & 0.65 & $-0.47 \ldots 2.11$ & 0 \\
$\mathrm{CO}(\mathrm{ppb})$ & 168 & -6.54 & 1.00 & $-8.52 \ldots-4.55$ & 1 \\
$\mathrm{~N}_{2} \mathrm{O}(\mathrm{ppb})$ & 182 & -0.003 & 0.028 & $-0.059 \ldots 0.053$ & 0 \\
$\mathrm{SF}_{6}(\mathrm{ppt})$ & 168 & -0.020 & 0.004 & $-0.027 \ldots-0.014$ & 1 \\
\hline
\end{tabular}

and at MPI-BGC laboratory was $0.92 \mathrm{ppb}$ (Manning et al., 2009). This similarity between flasks and cylinders comparisons indicates a possible $\mathrm{BIK} \mathrm{CH}_{4}$ calibration scale offset, and necessitates further investigation.

The CO mean difference of $-6.54 \pm 1.98 \mathrm{ppb}$ was found to be statistically significant. Comparisons made using the previously mentioned high pressure "Cucumber" cylinders showed a much smaller difference, of about $-1.3 \mathrm{ppb}$, thus a calibration scale bias cannot explain most of the difference observed from the comparison with flask samples. An increase of the $\mathrm{CO}$ mole fraction in stored flasks could be the reason. Such an increase, of about $0.047 \mathrm{ppb} /$ day, has been observed in the same type of flasks, during storage tests performed at MPI-BGC (A. Jordan, MPI-BGC, personal communication). The flasks sampled at Bialystok were stored on average $80.8 \pm 46.7$ days, which could explain a difference of about $3.8 \pm 2.2 \mathrm{ppb}$. However, more tests are necessary in order to definitely exclude any problem within the air sampling sub-system of the in-situ measurement.

According to the t-test, the $\mathrm{SF}_{6}$ mean difference between the in-situ measurement and flask samples is also statistically significant. However, this difference is very small $(-0.02 \mathrm{ppt})$, therefore will not represent a problem for interpreting the measurement data.

For each species, the differences between in-situ measurements and flask samples were tested for possible dependence on mole fraction, but no significant correlations were found.

\subsection{General characteristics of the time series}

Results of continuous measurements from several northern mid-latitudes tall tower stations have been described in the literature (e.g. Bakwin et al., 1995, 1998; Haszpra, 2008; Hurst et al., 1997; Kozlova et al., 2008; Stephens et al., 2007; Thompson et al., 2009). The data show typically high variability on time scales from hours to weeks, due to the proximity of the strongly localized continental fluxes. Tall tower $\mathrm{CO}_{2}$ data show strong diurnal cycles and seasonal variations stronger than at marine or mountain stations situated at the same latitudes (e.g. Bakwin et al., 1995), due to the influence of the regional land biosphere. There are, however, differences between the general variability patterns at tall tower stations from different locations. For example, the amplitude of the $\mathrm{CO}_{2}$ seasonal cycles is determined by the activity of the land biosphere and thus varies with latitude. The short term variations are influenced by the upstream surface emissions and by the atmospheric transport, and thus by the regional particularities of these.

The remainder of this paper presents the main characteristics of the in-situ measurement data collected at Bialystok, in terms of general variability, and seasonal and diurnal cycles.

\subsection{1 $\mathrm{CO}_{2}$ and $\mathrm{O}_{2} / \mathrm{N}_{2}$}

Variations of atmospheric $\mathrm{CO}_{2}$ and $\mathrm{O}_{2} / \mathrm{N}_{2}$ are largely anticorrelated, because during the processes of respiration, photosynthesis and fossil fuel combustion $\mathrm{O}_{2}$ is consumed when $\mathrm{CO}_{2}$ is produced and vice versa. Therefore they will be discussed together in what follows.

The $\mathrm{CO}_{2}$ and $\mathrm{O}_{2} / \mathrm{N}_{2}$ records (Fig. 5) show anti-correlated trends and seasonal cycles, and superimposed short term (diurnal and synoptic scale) variations which are also largely anticorrelated. The patterns and amplitude of short term variations depend on season and sampling height. During the warm seasons, the diurnal cycles with amplitude of up to $70 \mathrm{ppm}$ for $\mathrm{CO}_{2}$ and $300-400$ per meg for $\mathrm{O}_{2} / \mathrm{N}_{2}$ clearly dominate the variability at the sampling levels close to the ground. The amplitude of the diurnal signal gradually decreases with the sampling height, so that at $300 \mathrm{~m}$ above ground level it is comparable with the amplitude of the synoptic scale variations. During the cold season, the synoptic scale events become the dominant type of variability at all sampling heights. The synoptic events (which dominate the variability of the mole fractions in the air sampled at $300 \mathrm{~m}$ ) have the same order of magnitude throughout the year; therefore the short term variability of the data series from $300 \mathrm{~m}$ does not show large seasonal differences. Vertical gradients are largest in summer time, but do appear in all seasons. During summer, the vertical gradients follow a daily cycle, whilst during winter they do not have a regular evolution.

The relatively high variability of the $\mathrm{CO}_{2}$ and $\mathrm{O}_{2} / \mathrm{N}_{2}$ data series is characteristic of continental measurements, due to the proximity of strong sources and sinks. The nocturnal enhancements of $\mathrm{CO}_{2}$ at the lower sampling levels indicate strong local and regional sources. 

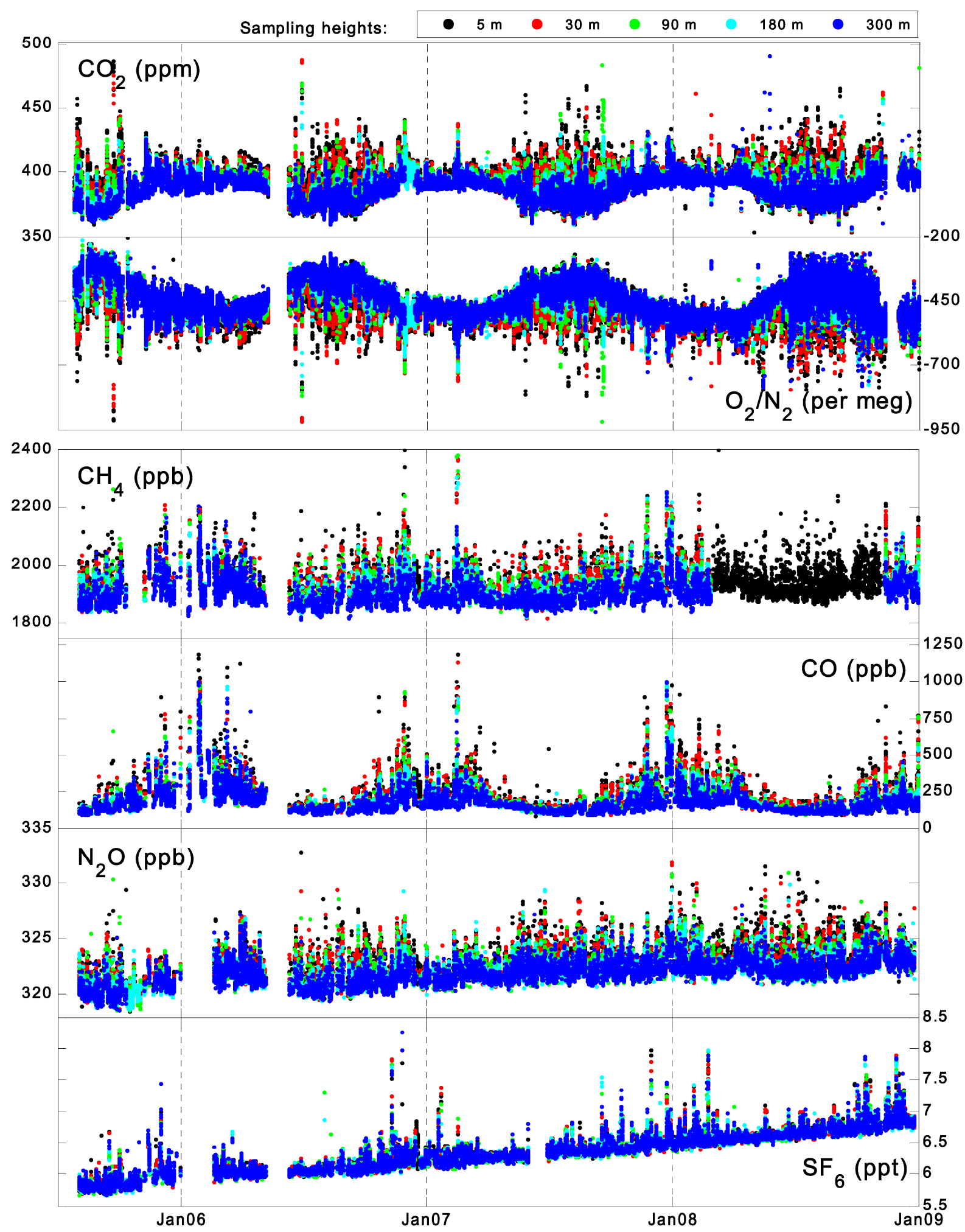

Fig. 5. Time series of $\mathrm{CO}_{2}, \mathrm{O}_{2} / \mathrm{N}_{2}, \mathrm{CH}_{4}, \mathrm{CO}, \mathrm{N}_{2} \mathrm{O}$ and $\mathrm{SF}_{6}$, from different sampling heights. $\mathrm{CH}_{4}$ data between March and November 2008 , except for the $5 \mathrm{~m}$ height, were excluded following quality check. $\mathrm{O}_{2} / \mathrm{N}_{2}$ data between June and November 2008 show large noise due to an instrumental problem; they were not eliminated during the quality check, but their potential use is limited by the large noise. 


\subsection{2 $\mathrm{CH}_{4}$}

The $\mathrm{CH}_{4}$ record (Fig. 5) is characterized by high short term variability, on the order of 200-300 ppb. Strong diurnal signals dominate the variability at low sampling levels during summer. The synoptic signals are stronger during winter than during summer. The difference between the seasons consists mainly in differences in the data variability and in the vertical gradients. The large vertical gradients, with generally higher mole fractions at lower sampling levels, suggest the existence of strong local to regional sources.

\subsubsection{CO}

CO (Fig. 5) has a seasonally varying atmospheric lifetime primarily caused by seasonality in $\mathrm{OH}$ radical, the main $\mathrm{CO}$ sink. This is reflected in the observed mole fractions at BIK. The seasonality is mostly manifested as difference in variability, although a difference in "baseline" can also be observed. During summer, the diurnal variations and the synoptic signal have comparable amplitudes. This is unlike the behaviour of $\mathrm{CO}_{2}$ and $\mathrm{CH}_{4}$ mole fractions, for which during summer the diurnal variations are dominant. The strong winter time $\mathrm{CO}$ signals, often above $600 \mathrm{ppb}$, are likely due to increased anthropogenic emissions combined with a longer CO lifetime during the cold season. Vertical gradients with higher mole fraction at lower sampling levels are apparent throughout the year but the differences between the sampling levels are usually small compared to the general data variability. This indicates that the main $\mathrm{CO}$ sources are not local, but distributed over a wider area.

\subsection{4 $\quad \mathrm{N}_{2} \mathrm{O}$}

The $\mathrm{N}_{2} \mathrm{O}$ time series is shown in Fig. 5. The summer time variability of $\mathrm{N}_{2} \mathrm{O}$ is dominated by the diurnal signal, similarly to $\mathrm{CO}_{2}$ and $\mathrm{CH}_{4}$. Vertical gradients with higher mole fractions at lower sampling levels show the existence of local to regional sources. The variability is relatively small, with typical signals of a few ppb above the background, and slightly larger during the warm seasons.

\subsection{5 $\mathrm{SF}_{6}$}

The $\mathrm{SF}_{6}$ time series (Fig. 5) has little short term variability, with only few "events" reaching a few ppt above the background mole fraction. Unlike the other species measured at Bialystok, during most of the pollution events observed, the vertical gradient was either absent or reversed, that is, the highest sampling height showed the largest increase in mole fraction. These features, together with the general absence of a discernible vertical gradient, suggest that there are no significant $\mathrm{SF}_{6}$ sources in the vicinity of the station.

\subsection{Trends and seasonal cycles}

\subsubsection{Data processing}

In order to derive the long-term trends and seasonal amplitudes, the Bialystok data have been processed as follows. Only the afternoon data have been selected, that is, between 11:00 and 16:00 GMT, which means 13:00-18:00 local time (during summer). Weekly trimmed averages are calculated from the selected data excluding the highest and the lowest $10 \%$ of the data. The function shown below, consisting of a linear trend and a three harmonics seasonal cycle is fitted to the weekly averages by a linear least squares method.

$$
f(x)=a_{0}+a_{1} x+\sum_{n=1}^{3}\left(b_{n} \sin \left(\frac{2 \pi}{365} n x\right)+c_{n} \cos \left(\frac{2 \pi}{365} n x\right)\right)
$$

where $x$ is the time in days since the start of the measurements; $a_{0}, a_{1}, b_{n}$ and $c_{n}$ are the fitted coefficients.

The trend for each species is calculated by fitting the function described above to the data from $300 \mathrm{~m}$ height, which has the lowest short term variability. For the trend estimation we use a robust linear least squares method (which reduces the weight of outliers using bisquare weights; Matlab Curve Fitting Tool 1.2). The time series of different sampling heights are then de-trended using the trend previously calculated, and the harmonic function is fitted (non-robust) in order to obtain the seasonal curves. In Figs. 6 and 7, the seasonal cycles are plotted normalized to the mean of one "reference" sampling height, in order to preserve the relative position of the curves corresponding to different heights. The uncertainties specified below for the trend values are given by the $95 \%$ confidence intervals.

\subsubsection{Trends and seasonal cycles of $\mathrm{CO}_{2}$ and $\mathrm{O}_{2} / \mathrm{N}_{2}$}

The $\mathrm{CO}_{2}$ average growth rate between July 2005 and December 2008, estimated from the Bialystok record, was $2.02 \pm 0.46 \mathrm{ppm} /$ year. This result is consistent with the recent World Meteorological Organization (WMO) estimates of the global $\mathrm{CO}_{2}$ increase during 2007 and 2008 (1.9, respectively $2 \mathrm{ppm}$ ) and over the last ten years (1.93 ppm/year) (WMO Greenhouse Gas Bulletin No. 4 and No. 5, 2008, 2009). $\mathrm{O}_{2} / \mathrm{N}_{2}$ decreased during the same period with an average rate of $23.2 \pm 2.5 \mathrm{per} \mathrm{meg} / \mathrm{year}$. For comparison, Thompson et al. (2009) observed at another European station (Ochsenkopf, Germany, OXK) a smaller $\mathrm{O}_{2} / \mathrm{N}_{2}$ decrease rate of $16.3 \pm 3.1$ per meg/year (using data covering a partly different time interval, July 2006 to July 2008). Another study (Kozlova et al., 2008), using data from Shetland Islands, United Kingdom (SIS), estimated an $\mathrm{O}_{2} / \mathrm{N}_{2}$ decrease of 18.6 per meg/year over the period 2004 to 2008 . These results are in line with the decrease rate of $20 \pm 1$ per meg over the previous period July 2000 to July 2005, as reported by Sirignano et al. (2010), using data from Mace Head, Ireland (MHD) and Lutjewad, the Netherlands (LUT). 
Table 4. Trends and seasonal amplitudes for the species measured in-situ at Bialystok.

\begin{tabular}{lrrrr}
\hline Species (unit) & $\begin{array}{r}\text { Average growth } \\
\text { rate }\end{array}$ & $\begin{array}{r}\text { Seasonal } \\
\text { ampl. at } 300 \mathrm{~m}\end{array}$ & $\begin{array}{r}\text { Seasonal } \\
\text { ampl. at 30 m }\end{array}$ & Data period \\
\hline $\mathrm{CO}_{2}(\mathrm{ppm})$ & $2.02 \pm 0.46$ & 20 & 25 & Aug 05-Jun 08 \\
$\mathrm{O}_{2} / \mathrm{N}_{2}$ (per meg) & $-23.2 \pm 2.5$ & 156 & 161 & Aug 05-Jun 08 \\
$\mathrm{APO}$ (per meg) & $-12.2 \pm 0.9$ & 49 & 43 & Aug 05-Jun 08 \\
$\mathrm{CH}_{4}$ (ppb) & $10.1 \pm 4.4$ & 64 & 88 & Aug 05-Dec 08 \\
$\mathrm{CO}(\mathrm{ppb})$ & $-8.3 \pm 5.3$ & 132 & 201 & Aug 05-Dec 08 \\
$\mathrm{N}_{2} \mathrm{O}(\mathrm{ppb})$ & $0.67 \pm 0.08$ & 0.69 & 0.79 & Aug 05-Dec 08 \\
$\mathrm{SF}_{6}$ (ppt) & $0.29 \pm 0.01$ & 0.11 & 0.14 & Aug 05-Dec 08 \\
\hline
\end{tabular}

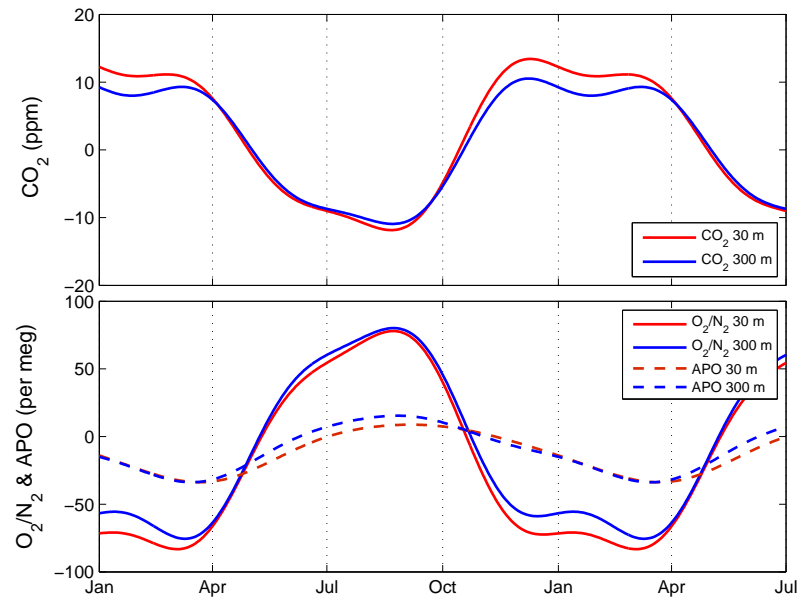

Fig. 6. Seasonal cycles of $\mathrm{CO}_{2}, \mathrm{O}_{2} / \mathrm{N}_{2}$ and $\mathrm{APO}$, at two sampling heights.

There are several large scale processes which involve absorption or emission of $\mathrm{CO}_{2}$ and $\mathrm{O}_{2}$ and which are characterized by seasonal variability: the land and ocean biosphere activity, the thermally induced variations of solubility in ocean water, and the seasonal patterns of atmospheric circulation. The seasonal variability of anthropogenic emissions is very small compared to the processes listed before. There is, however, an essential difference between the two species regarding the gas exchange between ocean and atmosphere. For $\mathrm{CO}_{2}$, this exchange is buffered by chemical reactions in sea water, while $\mathrm{O}_{2}$ is not affected. This translates into a large difference in equilibration time between the ocean and atmosphere for the two species: about one year for $\mathrm{CO}_{2}$ and about three weeks for $\mathrm{O}_{2}$ (Broecker and Peng, 1982). As a consequence, the activity of the ocean biosphere and the thermally induced variations of solubility do not affect significantly the seasonal cycle of the atmospheric $\mathrm{CO}_{2}$, while having a significant effect on the $\mathrm{O}_{2} / \mathrm{N}_{2}$ seasonal cycle. The seasonal variation of atmospheric $\mathrm{CO}_{2}$ therefore is mainly due to the land biosphere and to the seasonal pattern of atmospheric circulation, while the seasonal variation of $\mathrm{O}_{2} / \mathrm{N}_{2}$ has, in addition, an important oceanic component (Keeling and Shertz, 1992).
The oceanic component of the $\mathrm{O}_{2} / \mathrm{N}_{2}$ seasonal cycle has been computed in previous works (e.g. Keeling et al., 1998b) by subtracting the land biosphere component from the total $\mathrm{O}_{2} / \mathrm{N}_{2}$ seasonal cycle. The land biosphere component is calculated based on the seasonal cycle of $\mathrm{CO}_{2}$, assuming an average molar ratio between the $\mathrm{O}_{2} / \mathrm{N}_{2}$ and $\mathrm{CO}_{2}$ variations due to the land biosphere of -1.1 (Severinghaus, 1995). The oceanic component of the $\mathrm{O}_{2} / \mathrm{N}_{2}$ signal calculated in this way is referred to as APO (Atmospheric Potential Oxygen) defined by Stephens et al. (1998). The simplified definition of APO (ignoring very minor influences from $\mathrm{CH}_{4}$ and $\mathrm{CO}$ ) is:

$$
\begin{aligned}
& \mathrm{APO}(\text { per meg }) \\
& =\mathrm{O}_{2} / \mathrm{N}_{2}(\text { per meg })+1.1 \times\left(\mathrm{CO}_{2}(\text { ppm })-350\right) / 0.20946
\end{aligned}
$$

where 0.20946 is the standard mole fraction of $\mathrm{O}_{2}$ in air; 350 is an arbitrary reference $\mathrm{CO}_{2}$ mole fraction (Stephens et al., 1998).

Figure 6 shows the three-harmonic seasonal cycles of $\mathrm{CO}_{2}, \mathrm{O}_{2} / \mathrm{N}_{2}$ and APO, corresponding to two sampling heights: $30 \mathrm{~m}$ and $300 \mathrm{~m}$ above ground level. Table 4 lists the trends and the characteristics of the seasonal cycles of all species measured in-situ at Bialystok, and of APO.

$\mathrm{CO}_{2}$ exhibits a seasonal cycle with a peak to peak amplitude of about $20 \mathrm{ppm}$ for measurements from the $300 \mathrm{~m}$ level (blue line in Fig. 6), the amplitude increasing for lower sampling heights, up to about 25 ppm at $30 \mathrm{~m}$ (red line in Fig. 6). The lower sampling heights have higher seasonal amplitude due to the stronger influence from local $\mathrm{CO}_{2}$ emissions during winter and from the $\mathrm{CO}_{2}$ biosphere uptake during summer. The largest difference between the sampling heights can be seen during the cold season, but this could be due to our data processing method (only afternoon data have been considered, i.e. the time when the vertical mixing is strong, especially during summer). The minimum of the $\mathrm{CO}_{2}$ seasonal cycle is in August, and there is a double maximum in December and in February-March. A possible explanation for the first maximum is enhanced heterotrophic respiration in autumn after the leaf fall, when the available quantity of fresh organic matter is higher. The second maximum could be due to an increase of gas exchange with the soil after the snow melted. 
The observed seasonal amplitude can be compared with results from other stations in northern hemisphere, with the reserve that the absolute values are dependent on the data processing method (the same is valid for the $\mathrm{O}_{2} / \mathrm{N}_{2}$ and APO comparisons in the following paragraphs). As $\mathrm{CO}_{2}$ seasonal cycle is mainly driven by land fluxes, the amplitude tends to be larger at intra-continental sites. For example, Bakwin et al. (1998) found the seasonal cycles at intra-continental stations in US to be larger that at marine boundary layer (MBL) stations: 16.9 and 22.4 at North Carolina (NC) respectively Wisconsin (WI) tall towers, and 9.7 and $10.9 \mathrm{ppm}$ at MBL sites at the same latitudes. At OXK (a tall tower situated on a mountain summit) the $\mathrm{CO}_{2}$ seasonal amplitude is $15.5 \mathrm{ppm}$ (Thompson et al., 2009). Sirignano et al. (2010) found seasonal amplitudes of $14 \mathrm{ppm}$ and $16 \mathrm{ppm}$ at MDH and LUT. Similar amplitude with the $\mathrm{CO}_{2}$ seasonal cycle at BIK, and similar variation with the sampling height, were observed at Hegyhátsál, Hungary (HUN) (Haszpra et al., 2008): approximately 25 and $30 \mathrm{ppm}$, from $115 \mathrm{~m}$ and $10 \mathrm{~m}$ a.g.l. Kozlova et al. (2008) reported a larger seasonal amplitude of $26.6 \mathrm{ppm}$ at ZOTTO, Siberia.

The $\mathrm{O}_{2} / \mathrm{N}_{2}$ seasonal cycle is to a large degree anticorrelated with the seasonal cycle of $\mathrm{CO}_{2}$, even to the point of exhibiting corresponding double minima, the main drivers being processes which involve both species. The correlation is not perfect, due to the oceanic component of the $\mathrm{O}_{2} / \mathrm{N}_{2}$ cycle which has no equivalent for $\mathrm{CO}_{2}$. The peak to peak amplitude of the $\mathrm{O}_{2} / \mathrm{N}_{2}$ seasonal cycle is about 156 per meg (corresponding to $29.5 \mathrm{ppm}$ in $\mathrm{CO}_{2}$ ) at $300 \mathrm{~m}$, and 161 per meg $\left(30.5 \mathrm{ppm} \mathrm{CO} \mathrm{CO}_{2}\right)$ at $30 \mathrm{~m}$ above ground. The timing of the $\mathrm{O}_{2} / \mathrm{N}_{2}$ maximum and minima mirrors those of $\mathrm{CO}_{2}$. Reported seasonal amplitudes of $\mathrm{O}_{2} / \mathrm{N}_{2}$ at other stations at comparable latitudes are: 153 per meg and 102 per meg at LUT and MHD (Sirignano et al., 2010); 190 per meg and 171 per meg at Puy de Dome, France and from air sampling above Griffin Forest, UK (Sturm et al., 2005); 135 per meg at OXK (Thompson et al., 2009); 163 per meg and 134 per meg at SIS and at ZOTTO (Kozlova et al., 2008).

The APO seasonal cycle has a peak to peak amplitude of 49 per meg at $300 \mathrm{~m}$, and 43 per meg at $30 \mathrm{~m}$. Compared to the total amplitude of the $\mathrm{O}_{2} / \mathrm{N}_{2}$ seasonal variation, the oceanic component represents $31 \%$ (at $300 \mathrm{~m}$ ) and $27 \%$ (at $30 \mathrm{~m}$ ). The APO minimum is in March, and the maximum in August-September. Reported seasonal amplitudes of APO at other stations at comparable latitudes are: 67 per meg and 45 per meg at LUT and MHD (Sirignano et al., 2010); 43 per meg at OXK (Thompson et al., 2009); 95 per meg and 51 per meg at SIS and at ZOTTO (Kozlova et al., 2008).

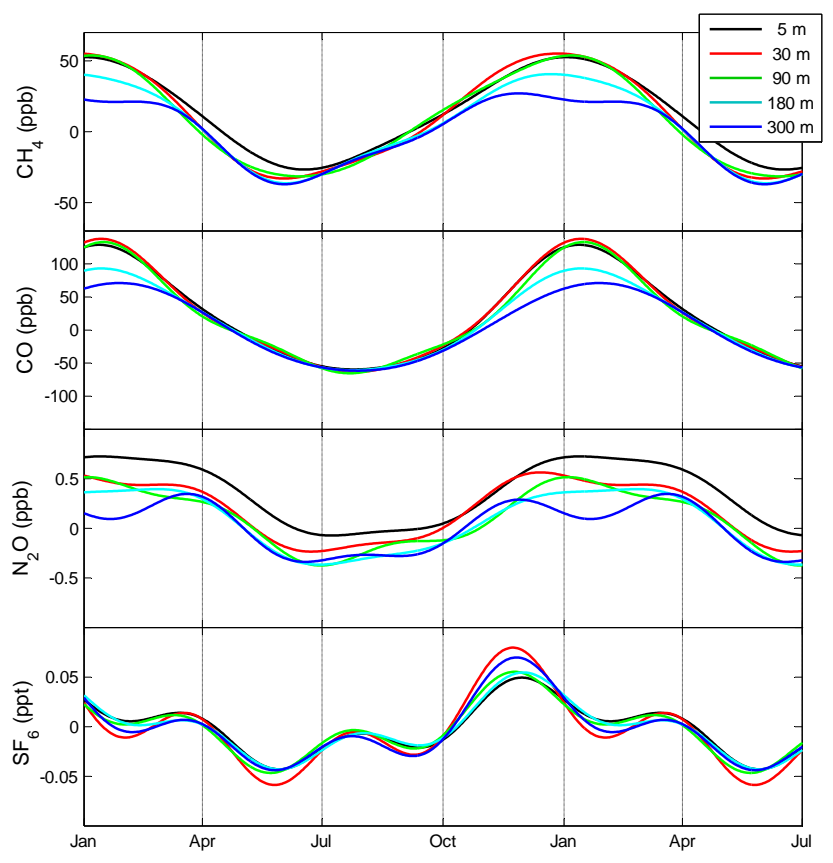

Fig. 7. Seasonal cycles of $\mathrm{CH}_{4}, \mathrm{CO}, \mathrm{N}_{2} \mathrm{O}$ and $\mathrm{SF}_{6}$. The colours represent different sampling heights.

\subsubsection{Trends and seasonal cycles of $\mathrm{CH}_{4}, \mathrm{CO}, \mathrm{N}_{2} \mathrm{O}$ and $\mathrm{SF}_{6}$}

Figure 7 shows the three-harmonic seasonal cycles of $\mathrm{CH}_{4}$, $\mathrm{CO}, \mathrm{N}_{2} \mathrm{O}$ and $\mathrm{SF}_{6}$ from different sampling heights.

For $\mathrm{CH}_{4}$, in contrast to the other species, the trend was calculated using the data from the lowest sampling height, because for a large part of 2008 the data for the other sampling heights are missing. The average increase rate over the whole period (1 August 2005-31 December 2008) is $10.1 \pm 4.4 \mathrm{ppb} /$ year. It is evident from the large uncertainty that the calculated trend for $\mathrm{CH}_{4}$ is not very well defined, which is due to the shortness of the data series combined with the relatively large variability. The $\mathrm{CH}_{4}$ trend calculated at Bialystok is very close to the results from another recent study (Thompson et al., 2009), which reported increase rates of 9.8 and $10.4 \mathrm{ppb} /$ year at two other European locations (OXK and SIS), using data covering partly the time interval of this work. Both our results and those of Thompson et al. (2009) are higher than the global increase during 2007 and 2008 of about $7 \mathrm{ppb} /$ year, estimated from WMO-GAW global greenhouse gas monitoring network (WMO, 2009). Another global estimate (Dlugokencky et al., 2009) revealed an increase of $8.3 \pm 0.2 \mathrm{ppb}$ in 2007, but a lower increase of $4.4 \pm 0.2 \mathrm{ppb}$ in 2008. Dlugokencky et al. (2009) determined that the most likely drivers of the $\mathrm{CH}_{4}$ resumed increase during 2007 and 2008 were high temperature in the Arctic and high precipitation in the tropics. The discrepancy between our increase rate estimate and the global ones could in principle be related to the large uncertainty of our result. However, the results of Thompson et al. (2009) for two other European 
stations (OXK and SIS) support our estimate. A higher than global increase rate at these three European stations (one of them being a remote marine site) could be explained if the recent global increase were caused by an imbalance between sources and sinks in Northern Hemisphere.

The peak to peak amplitude of the $\mathrm{CH}_{4}$ seasonal cycle ranges from $64 \mathrm{ppb}$ at $300 \mathrm{~m}$ to about $88 \mathrm{ppb}$ at $30 \mathrm{~m}$ above ground, with the maximum in December and a relatively sharp minimum in May-June. The curve corresponding to the $300 \mathrm{~m}$ sampling height has a different shape compared to the other heights, having the absolute maximum in November followed by a slow decrease and a secondary maximum in March. In comparison to the other species, $\mathrm{CH}_{4}$ starts rising earlier after the spring minimum, a fact which can likely be attributed to temperature enhanced emissions from wetlands and to burning of agricultural residues during summer and autumn. The large differences between the sampling heights, especially during winter, indicate the existence of significant regional sources.

The $\mathrm{CO}$ trend calculated from this data set is $(-8.3 \pm 5.3) \mathrm{ppb} / \mathrm{year}$. Considering the large intra- and inter-annual variability of $\mathrm{CO}$ and the shortness of the data series, this decreasing trend result might be not representative.

The CO seasonal cycle has an amplitude of about $130 \mathrm{ppb}$ at $300 \mathrm{~m}$, and increases to about $200 \mathrm{ppb}$ at lower sampling heights. The maximum is in January, slightly delayed compared to the maximum of $\mathrm{CH}_{4}$. In autumn $\mathrm{CO}$ starts increasing later than $\mathrm{CH}_{4}$, the low $\mathrm{CO}$ mole fraction level season is longer, and the minimum of the seasonal cycle is about two months delayed in comparison with $\mathrm{CH}_{4}$. The $\mathrm{CO}$ seasonal cycle reflects the seasonality of its main sink, the reaction with $\mathrm{OH}$ radical (which is in greater abundance in the summer), and the seasonality of atmospheric mixing. Although the reaction with $\mathrm{OH}$ radical is also the main sink for $\mathrm{CH}_{4}$, the effect of the $\mathrm{OH}$ seasonality is much larger for $\mathrm{CO}$ than for $\mathrm{CH}_{4}$. The difference is related to the higher reactivity (and faster atmospheric turnover) of $\mathrm{CO}$ compared to $\mathrm{CH}_{4}$. As with $\mathrm{CH}_{4}$, the winter time large differences in $\mathrm{CO}$ between the sampling heights indicate significant local sources.

$\mathrm{N}_{2} \mathrm{O}$ increased during our measurement period with an average rate of $0.67 \pm 0.08 \mathrm{ppb} / \mathrm{year}$, a value lower than other recent estimates. The global increase estimated from the WMO-GAW global greenhouse gas monitoring network was $0.8 \mathrm{ppb}$ and $0.9 \mathrm{ppb}$ in 2007 and 2008, and $0.78 \mathrm{ppb}$ when averaged over the last ten years (WMO, 2008, 2009). Similarly, Haszpra et al. (2008) reported a trend of $0.7 \mathrm{ppb} /$ year based on flasks sampled at HUN and analyzed by NOAA-ESRL GMD (http://www.esrl.noaa.gov/ $\mathrm{gmd} / \mathrm{ccgg} /$ flask.html). Thompson et al. (2009), estimated increase rates of $0.99 \mathrm{ppb} / \mathrm{year}$ and $0.95 \mathrm{ppb} / \mathrm{yr}$ for OXK and SIS, respectively. We suspect that the difference between the estimates at Bialystok and other sites is partly due to the irregular variability combined with the shortness of the data set.
The $\mathrm{N}_{2} \mathrm{O}$ seasonal cycle at Bialystok has a relatively small amplitude of about $0.7 \mathrm{ppb}$ at $300 \mathrm{~m}$, which increases to $0.8 \mathrm{ppb}$ at $30 \mathrm{~m}$. The different sampling heights have different shapes, but the tendency is to have a double minimum in June and September, and a double maximum in November and March. This feature is most visible at the highest sampling height. A series of recent studies (Haszpra et al., 2008; Jiang et al., 2007; Thompson et al., 2009) presented similar bimodal seasonal cycles of $\mathrm{N}_{2} \mathrm{O}$ in Europe. The reported seasonal amplitudes are quite diverse, for example $0.37 \mathrm{ppb}$ at OXK (Thompson et al., 2009), 0.57 at MHD (Jiang et al., 2007) and 1.4 at HUN (Haszpra et al., 2008). The timing of minima and maxima is also variable, however most stations tend to have a minimum in August-September. BIK and MHD show a maximum in March, while OXK and HUN show a minimum at this time. Vice-versa, BIK shows a minimum in June while HUN and OXK show a maximum.

The rather complicated seasonal cycle is due to interfering influences of different sources with the atmospheric circulation. The soil emission is temperature dependent, therefore stronger during summer, with an additional influence due to the intermittent use of fertilizer in agriculture. Anthropogenic emissions could have a small seasonality, being higher during winter due to biomass burning for home heating. Besides these, $\mathrm{N}_{2} \mathrm{O}$ seasonal cycle includes most probably a component due to atmospheric (including stratospheric) circulation (Levin et al., 2002, Jiang et al., 2007), as indicated by the correlation with the seasonal cycle of $\mathrm{SF}_{6}$ (see also next paragraph), and possibly a component due to the seasonality of the oceanic source (Nevison et al., 2004). A striking feature is the offset between the lowest sampling height $(5 \mathrm{~m})$ and the others, quite constant through the year. This offset suggests a strong and relatively constant source in the near vicinity.

$\mathrm{SF}_{6}$ increased constantly during the time of our measurement, with an average rate of $0.29 \pm 0.01 \mathrm{ppt} /$ year. $\mathrm{SF}_{6}$ shows a weak but statistically significant seasonal cycle. The $\mathrm{SF}_{6}$ seasonal cycle is bimodal, with an absolute maximum in November and a secondary maximum in March, and minima in May-June and September. The amplitude varies between 0.09 and $0.14 \mathrm{ppb}$ for different sampling heights, but the differences between the sampling heights are not statistically significant. Haszpra et al. (2008) observed a similar bimodal $\mathrm{SF}_{6}$ seasonal cycle at $\mathrm{HUN}$, although the timing of minima and maxima is different (at HUN, maxima are in January and May, minima in March and July). $\mathrm{SF}_{6}$ has no known seasonally varying sources, thus the observed seasonal cycle most probably reflects the seasonal evolution of atmospheric circulation (as also interpreted by Haszpra et al., 2008). If we compare the shape of the $\mathrm{SF}_{6}$ seasonal cycle with the other species, we can observe some similarities. The $\mathrm{CH}_{4}$ and $\mathrm{N}_{2} \mathrm{O}$ seasonal shape at $300 \mathrm{~m}$ reproduce somewhat attenuated the location of the three "peaks" from the $\mathrm{SF}_{6}$ curve. This suggests atmospheric circulation as one of the factors influencing the shape of the seasonal cycles, especially at the highest 
sampling height. Our result is consistent to the findings of Levin et al. (2002). Using aircraft measurements across the Eurasian continent, Levin et al. (2002) observed correlated seasonal cycles in $\mathrm{SF}_{6}$ and $\mathrm{N}_{2} \mathrm{O}$, and indicated atmospheric transport patterns as probable cause, with a significant contribution from stratosphere-troposphere exchange.

\subsection{Diurnal variations}

\subsubsection{Diurnal variations of $\mathrm{CO}_{2}$ and $\mathrm{O}_{2} / \mathrm{N}_{2}$}

The diurnal cycle of $\mathrm{CO}_{2}$ and its variation with the sampling height have been previously studied using data from tall tower measurements (e.g. Bakwin et al., 1995, 1998; Haszpra et al., 2008).

The average summer-time diurnal variation of $\mathrm{CO}_{2}$ at $\mathrm{BIK}$, calculated for the year 2006, is shown in Fig. 8a. During the warm season, atmospheric vertical mixing follows a diurnal periodicity, which overlaps with the diurnal cycle of the release and uptake of $\mathrm{CO}_{2}$ by respiration and photosynthesis of the biosphere, and with the diurnal cycle of the human activity. During day, when the net exchange between the biosphere and atmosphere is dominated by photosynthesis, the air is well mixed up to typically $1-3 \mathrm{~km}$. Thus the decrease in mole fraction due to photosynthesis is relatively minor, due to dilution in the air column. During night, photosynthesis stops and vertical mixing is weak, while respiration continues. The $\mathrm{CO}_{2}$ emitted by respiration accumulates near ground level. Thus strong increases of the mole fraction near the ground and also strong vertical gradients can be observed. Anthropogenic emissions also add a small contribution to the observed $\mathrm{CO}_{2}$ summer night-time increase.

The variations of atmospheric $\mathrm{O}_{2}$ are directly linked to the variations of $\mathrm{CO}_{2}$, because $\mathrm{O}_{2}$ is consumed when $\mathrm{CO}_{2}$ is produced (and vice versa) by respiration and photosynthesis, or when fossil fuels are burned. The diurnal cycle of $\mathrm{O}_{2} / \mathrm{N}_{2}$ ratio is therefore largely anti-correlated with the diurnal cycle of $\mathrm{CO}_{2}$.

In the cold season respiration is reduced and photosynthesis declines to non-significant level. Anthropogenic emissions and land biosphere respiration are of the same order of magnitude. Also, the diurnal periodicity of vertical mixing disappears; the air column of a few hundred meters above ground is most of the time well mixed, and temperature inversions appear at non-regular time intervals. Figure 9 shows the evolution over the year of the monthly averaged diurnal cycles of $\mathrm{CO}_{2}$ and $\mathrm{O}_{2} / \mathrm{N}_{2}$. It can be observed that the average diurnal variation decreases in amplitude or even becomes indistinguishable during the cold months.

\subsubsection{Diurnal variations of $\mathrm{CH}_{4}, \mathrm{CO}, \mathrm{N}_{2} \mathrm{O}$ and $\mathrm{SF}_{6}$}

Figure $8 \mathrm{~b}-\mathrm{e}$ presents the average summer-time diurnal cycles of $\mathrm{CH}_{4}, \mathrm{CO}, \mathrm{N}_{2} \mathrm{O}$ and $\mathrm{SF}_{6}$. At the first view, the mole fractions of $\mathrm{CH}_{4}, \mathrm{CO}$ and $\mathrm{N}_{2} \mathrm{O}$ follow a temporal pattern similar

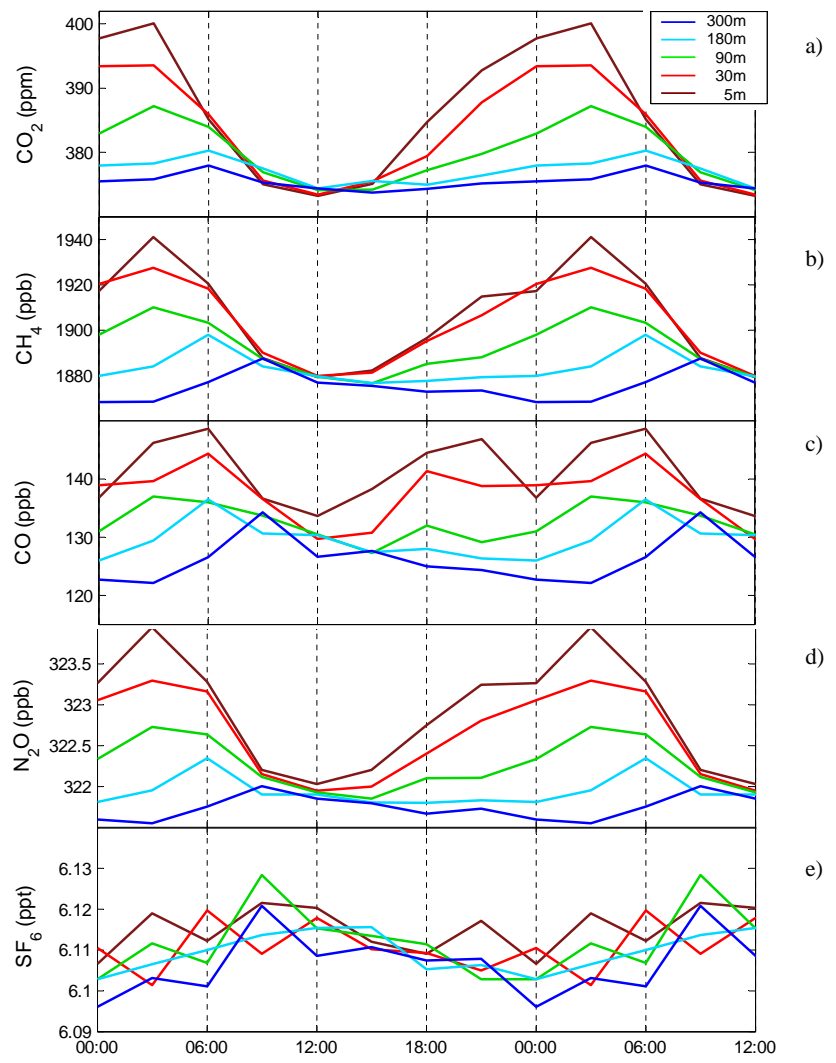

Fig. 8. Average diurnal variation of $\mathrm{CO}_{2}, \mathrm{CH}_{4}, \mathrm{CO}, \mathrm{N}_{2} \mathrm{O}$ and $\mathrm{SF}_{6}$ for the period June-September 2006. X-axis represents GMT time (=local time-2 h). The colours represent different sampling heights. The averages for 3 -h bins are calculated using a robust method, the lowest and the highest $5 \%$ of the data being dismissed. The first half of day was repeated for visual clarity.

to $\mathrm{CO}_{2}$. During day the vertical gradient is reduced by the strong vertical mixing of the air column. During night the vertical gradient increases and there is a strong accumulation at levels close to the ground. Similar patterns have been observed at other tall tower sites, for example by Hurst et al. (1997) and Haszpra et al. (2008).

There are however dissimilarities of the diurnal variations of different species, which reflect the differences in sources and sinks. The weak vertical gradient during day is opposite in sign for $\mathrm{CO}_{2}$ compared to $\mathrm{CH}_{4}, \mathrm{CO}$ and $\mathrm{N}_{2} \mathrm{O}$. During day the net $\mathrm{CO}_{2}$ flux into the atmosphere is negative due to photosynthesis. Thus the air sampled closer to the ground (where photosynthesis occur) is depleted in $\mathrm{CO}_{2}$ compared to the higher levels. On the other hand, $\mathrm{CH}_{4}, \mathrm{CO}$ and $\mathrm{N}_{2} \mathrm{O}$ are being emitted near the ground level, which results into higher mole fractions at sampling heights closer to the ground, as can be observed in Fig. 8. Related to this is the night time evolution of mole fractions at $300 \mathrm{~m}$ sampling height. After the vertical mixing has diminished, the mole fraction of $\mathrm{CO}_{2}$ at $300 \mathrm{~m}$ shows a slight increase, because the input of air depleted in $\mathrm{CO}_{2}$ by photosynthesis declined. In the same time, the mole fractions of $\mathrm{CH}_{4}, \mathrm{CO}$ and $\mathrm{N}_{2} \mathrm{O}$ at $300 \mathrm{~m}$ 


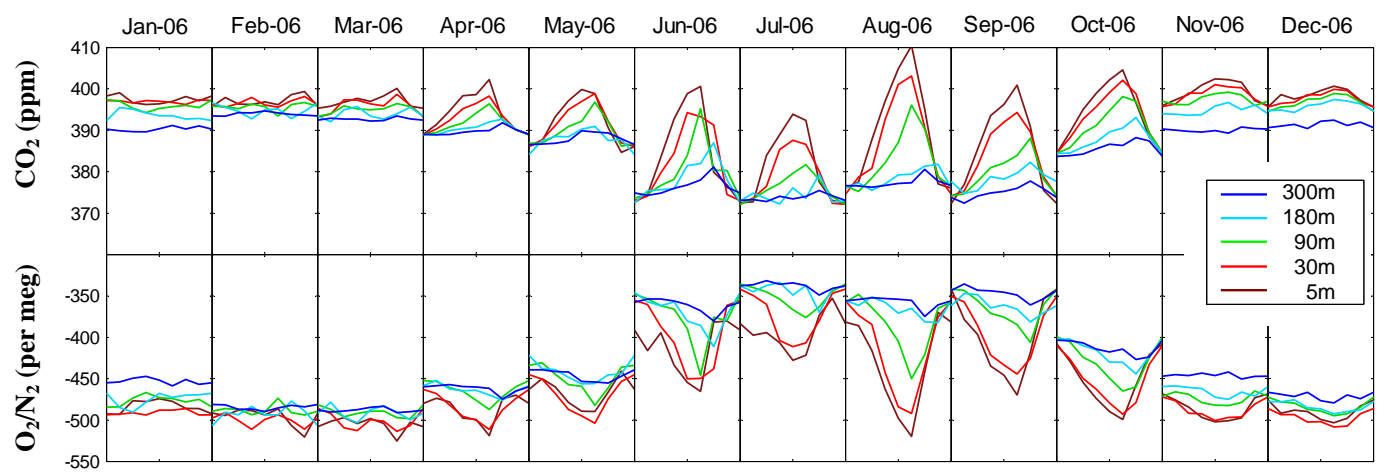

Fig. 9. Monthly averaged diurnal cycles of $\mathrm{CO}_{2}$ and $\mathrm{O}_{2} / \mathrm{N}_{2}$ for the year 2006. The upper panels show $\mathrm{CO}_{2}$ and the lower panels $\mathrm{O}_{2} / \mathrm{N}_{2}$. The colours represent different sampling heights. The $\mathrm{x}$-axis of each sub-plot covers a $24 \mathrm{~h}$ interval, centered on midnight.

decrease because the upwards transport of the gases emitted near ground level drastically reduced.

At midnight GMT (=02:00 local summer time), a partial minimum can be observed in the $\mathrm{CO}$ mole fraction at the sampling levels close to the ground, bracketed by evening and morning maxima. This evolution is consistent with the temporal variation of human activities. The decrease of the accumulation rate of $\mathrm{CH}_{4}$ and $\mathrm{N}_{2} \mathrm{O}$ near the ground around midnight can also probably be related to the decrease of the anthropogenic emissions. Around 06:00 GMT (=08:00 local summer time) the $\mathrm{CO}_{2}$ mole fraction near the ground decrease due to the joint effect of vertical mixing and photosynthesis onset. The morning decrease of the mole fraction of the other species is delayed because the decrease due to vertical mixing is partly counteracted by an increase of anthropogenic emissions.

Although part of the $\mathrm{CO}_{2}$ accumulated by night is due to anthropogenic emissions, the land biosphere respiration is the main $\mathrm{CO}_{2}$ source during summer. A rough estimation of the proportion of the anthropogenic $\mathrm{CO}_{2}$ in the total night time accumulation can be done by comparing the amplitudes of the vertical profiles of $\mathrm{CO}$ and $\mathrm{CO}_{2}$. The $\mathrm{CO}: \mathrm{CO}_{2}$ ratio specific to anthropogenic emissions, estimated by different authors (e.g. Bakwin et al., 1998; Gamnitzer et al., 2006), ranges usually between 10 and $25 \mathrm{ppb}$ :ppm for rural areas. Thus the lower limit of the average $\mathrm{CO}: \mathrm{CO}_{2}$ ratio specific to anthropogenic emissions in this region can be reasonably assumed to be about $10 \mathrm{ppb}$ :ppm. The maximum $\mathrm{CO}$ accumulation between $5 \mathrm{~m}$ and $300 \mathrm{~m}$ heights is about $25 \mathrm{ppb}$. This means that the anthropogenic $\mathrm{CO}_{2}$ accounts for up to $2.5 \mathrm{ppm}$ from the maximum night time vertical gradient of about $25 \mathrm{ppm}$. Assuming a higher average $\mathrm{CO}: \mathrm{CO}_{2}$ ratio for the anthropogenic emissions, for example $25 \mathrm{ppb}$ :ppm, leads to an even smaller proportion of anthropogenic $\mathrm{CO}_{2}$ from the total of $1 \mathrm{ppm}$, which is $4 \%$ from the total $\mathrm{CO}_{2}$ accumulation. This result is consistent with model simulations (e.g. Geels et al., 2007), which show that in this area, during summer, the land biosphere is responsible for most of the $\mathrm{CO}_{2}$ mole fraction variability.
An interesting feature visible in Fig. 8 is the strong correlation between the diurnal cycles of $\mathrm{CH}_{4}$ and $\mathrm{N}_{2} \mathrm{O}$. The $\mathrm{CH}_{4}: \mathrm{N}_{2} \mathrm{O}$ ratio calculated for different sampling heights varies between 32 (for $5 \mathrm{~m}$ ) and 40.3 (for $300 \mathrm{~m}$ ) and the correlation coefficients are higher than 0.96. The vertical mixing is one of the contributing factors to the diurnal variations of both species. However, if vertical mixing were the only cause for the diurnal cycles of $\mathrm{CH}_{4}$ and $\mathrm{N}_{2} \mathrm{O}$, and if the sources of these species were constant, then the night time increase would have been monotonous, similar to the one of $\mathrm{CO}_{2}$. The existence of a similar midnight dip for $\mathrm{CH}_{4}$ and $\mathrm{N}_{2} \mathrm{O}$ suggests that there are other contributing factors to the diurnal variations, which have similar temporal evolution for the two species. We interpret this feature as a reduction of anthropogenic emissions (e.g. industry, biomass burning) between the evening and morning peaks. This would be consistent with the larger dip observed in $\mathrm{CO}$, which has in larger proportion anthropogenic sources.

$\mathrm{SF}_{6}$ shows a very weak diurnal variation and no accumulation during night, which supports the idea mentioned before, that there are no significant local $\mathrm{SF}_{6}$ sources.

\section{Summary and concluding remarks}

The Bialystok tall tower station for atmospheric measurements of greenhouse gases and related tracers has been running since 2005. The system is designed to measure in-situ, quasi-continuously $\mathrm{CO}_{2}, \mathrm{O}_{2} / \mathrm{N}_{2}, \mathrm{CH}_{4}, \mathrm{CO}, \mathrm{N}_{2} \mathrm{O}$ and $\mathrm{SF}_{6}$ in air sampled at five heights of the tower, between 5 and $300 \mathrm{~m}$ above ground level. The gas analysers used are: a LiCor 7000 for $\mathrm{CO}_{2}$, an Oxzilla FC-2 for $\mathrm{O}_{2}$, and an Agilent 6890 gas chromatograph with FID and ECD detectors for $\mathrm{CH}_{4}$, $\mathrm{CO}, \mathrm{N}_{2} \mathrm{O}$ and $\mathrm{SF}_{6}$. Besides the in-situ measurements, flask samples are filled regularly and measured at Max-Planck Institute for Biogeochemistry for the same species and, in addition, for $\mathrm{H}_{2}, \mathrm{Ar} / \mathrm{N}_{2}$ and stable isotopes ${ }^{13} \mathrm{C}$ and ${ }^{18} \mathrm{O}$ in $\mathrm{CO}_{2}$.

In order to achieve the required precision while running unattended, the measurement system required careful optimization of gas handling and measurement procedures, as 
well as thorough quality check means. Some of the most important quality check means employed are: the system diagnostic parameters registered together with the mole fraction data, the measurements of the Target gases, and the intercomparisons using flask samples and high pressure cylinders.

The evaluation of the measurement performance after more than three years led to overall satisfactory results. For example, the precision, estimated as the long term reproducibility of the Target gas measurements, is within or close to the project goals. The comparison between the in-situ and the flask sample results, used to check the accuracy of the insitu measurements, revealed no statistically significant differences between the in-situ and the flask sample results for $\mathrm{CO}_{2}, \mathrm{O}_{2} / \mathrm{N}_{2}, \mathrm{CH}_{4}$ and $\mathrm{N}_{2} \mathrm{O}$, and only a very small difference of $0.02 \mathrm{ppt}$ for $\mathrm{SF}_{6}$. The same comparison, however, revealed a significant difference of about $6.5 \mathrm{ppb}$ between the in-situ and the flask sample $\mathrm{CO}$ results. The suspected main cause for this difference is the evolution of $\mathrm{CO}$ in flask samples, but an error within the in-situ measurement system cannot be excluded without further investigation.

This measurement setup proved to be suitable for long term unattended running at a relatively remote station. For an even more remote location, however, the large demand of high pressure gas cylinders, the requirements for laboratory temperature stability, and the relatively high power consumption could be inconvenient.

From the record covering more than three years, it was possible to characterize the typical variability features of the species measured. Generally, $\mathrm{CO}_{2}, \mathrm{O}_{2} / \mathrm{N}_{2}, \mathrm{CH}_{4}$ and $\mathrm{CO}$ show large short term variability on diurnal and synoptic time scales. During summer, large diurnal variations dominate the variability at lower sampling levels. Synoptic variations are present at all sampling levels through the year, and are stronger during winter in case of CO. Large vertical gradients develop during all seasons, and follow a diurnal periodicity during warm seasons. $\mathrm{N}_{2} \mathrm{O}$ shows the same features as the species above, but its variability is relatively small, with typical signals of only few ppb above the background. During the warm seasons, the $\mathrm{CO}_{2}$ and $\mathrm{O}_{2} / \mathrm{N}_{2}$ short term variability at Bialystok is due mainly to the land biosphere photosynthesis and respiration, with a small contribution from fossil fuel burning. In case of $\mathrm{CH}_{4}, \mathrm{CO}$ and $\mathrm{N}_{2} \mathrm{O}$, the diurnal pattern with morning and evening maxima correlated with the peaks of human activity suggests that anthropogenic emissions have an important contribution. $\mathrm{SF}_{6}$ record shows only few signals, generally no vertical gradients and no accumulation near ground during stable nights. These features suggest that there are no significant $\mathrm{SF}_{6}$ sources in the vicinity of the station.

Seasonal variations could be observed at Bialystok in all in-situ measured species. The seasonal cycles of $\mathrm{CO}_{2}$ and $\mathrm{O}_{2} / \mathrm{N}_{2}$ are mainly due to the land biosphere activity, with an oceanic component contributing to the $\mathrm{O}_{2} / \mathrm{N}_{2}$ cycle. CO seasonal cycle is strongly influenced by the seasonally variation of its main sink, the reaction with $\mathrm{OH}$ radical. $\mathrm{CH}_{4}$ and $\mathrm{N}_{2} \mathrm{O}$ seasonal cycles suffer possibly multiple influences from land management, biomass burning and soil freezing/thawing cycles. $\mathrm{SF}_{6}$ has no known seasonally varying sources, thus its seasonal cycle reflects probably the seasonality of atmospheric circulation.

As estimated from this dataset covering the period August 2005 to December 2008, the $\mathrm{CO}_{2}$ increased with an average of $2.02 \pm 0.46 \mathrm{ppm} / \mathrm{year}$ while $\mathrm{O}_{2} / \mathrm{N}_{2}$ decreased with an average of $-23.2 \pm 2.5$ per meg/year. The increase rate of $\mathrm{CH}_{4}$ of $10.1 \pm 4.4 \mathrm{ppb} /$ year is higher than recent estimates of the global $\mathrm{CH}_{4}$ increase, but consistent with other results in Europe. The CO trend estimated from this dataset is $(-8.3) \pm 5.3 \mathrm{ppb} /$ year, result which might not be significant considering the large variability combined with the shortness of the time series. $\mathrm{N}_{2} \mathrm{O}$ increased with a rate of $0.67 \pm 0.08 \mathrm{ppb} /$ year, which is smaller than other estimates. $\mathrm{SF}_{6}$ increased during the time of this measurement with an average rate of $0.29 \pm 0.01 \mathrm{ppt} /$ year.

The measurement system at Bialystok contributes to the general expertise in the field of high precision atmospheric measurements. In particular, Bialystok is one of the few stations worldwide which include in-situ, quasi-continuous measurements of atmospheric oxygen. The knowledge about the measurement setup and quality, and about the specifics of the data at this sampling station will be useful for data users, for example when selecting data according to representativity for a specific study.

The measurement station at Bialystok is meant to be operated on long term, as part of the European atmospheric monitoring network. The mole fraction data, coupled with inverse models, will be used to derive regional and continental fluxes of greenhouse gases. Besides this long-term purpose, the quasi-continuous data offer the possibility to study processes occurring of various time scales. The large local biospheric signals will permit observing the evolution of the land biosphere, for example the reaction to extreme weather events or the response to global warming. On the other hand, the location on the Eastern limit of the highly populated area of Western Europe gives the opportunity to observe regional anthropogenic emissions. The presence of well-defined vertical gradients can help to distinguish between signals from the different influence areas of the different sampling heights. The flat surrounding area results in a relatively simple atmospheric circulation, which makes the model simulations for this site less difficult. 


\section{Appendix A}

\section{Description of the gas chromatographic method} $-170206 . M$

GC oven temperature (ECD columns): $\quad 76^{\circ} \mathrm{C}$ Auxiliary oven temperature (FID columns): $\quad 60^{\circ} \mathrm{C}$

Run time:
BACK DETECTOR (ECD)

Temperature:

Anode purge flow:

Mode:

Makeup flow:

Makeup Gas Type:

Adjust offset:

Lit offset: $385^{\circ} \mathrm{C}$ (On)

$6.0 \mathrm{~mL} / \mathrm{min}(\mathrm{On})$

Constant makeup flow

$5.0 \mathrm{~mL} / \mathrm{min}(\mathrm{On})$

Nitrogen

60.00

1.0

\section{FRONT DETECTOR (FID)}

Temperature:

Hydrogen flow:

Air flow:

Mode: Constant makeup flow

Makeup flow:

Makeup Gas Type:

Flame:

Lit offset: $175^{\circ} \mathrm{C}($ On)

$50.0 \mathrm{~mL} / \mathrm{min}(\mathrm{On})$

$320.0 \mathrm{~mL} / \mathrm{min}(\mathrm{On})$

$5.0 \mathrm{~mL} / \mathrm{min}(\mathrm{On})$

Nitrogen

On

1.0

\section{AUX PRESSURE 3}

Gas Type: Nitrogen

Initial pressure: $\quad 1.000 \mathrm{bar}(\mathrm{On})$

AUX PRESSURE 4

Gas Type: $\quad$ Argon methane 5\%

Initial pressure: $\quad 3.000 \mathrm{bar}(\mathrm{On})$

\section{METHANISER}

Temperature: $\quad 385^{\circ} \mathrm{C}(\mathrm{On})$

\section{AUX PRESSURE 5}

Gas Type:

Initial pressure:
Argon methane 5\% 4.200 bar (On)

Table A1. Vavles table.

\begin{tabular}{llllll}
\hline Valve & Type & Description & Initial position & OFF & ON \\
\hline 1 & switching & FID injection & OFF & Sample load & Sample inject \\
2 & switching & ECD injection & OFF & Sample load & Sample inject \\
3 & switching & FID methaniser bypass & OFF & no bypass & bypass \\
4 & switching & ECD bypass & OFF & bypass & no bypass \\
5 & switching & signal to Labview & OFF & 0 & 1 \\
6 & switching & between sample loops & ON & closed & open \\
7 & switching & MFC valve control & OFF & closed & open \\
8 & switching & Sample inlet & ON & closed & open \\
\hline
\end{tabular}


Table A2. Time table.

\begin{tabular}{|c|c|c|c|c|}
\hline Time & Specifier & Parameter \& Setpoint & Detector & Comment \\
\hline 0.01 & Aux 3 Pressure & $0.00 \mathrm{bar}$ & FID & $\begin{array}{l}\text { pressure decrease needed for Valve } 3 \text { switching, otherwise the } \\
\text { FID flame is blown off }\end{array}$ \\
\hline 0.01 & Valve 5 & On & & start signal to Labview program \\
\hline 0.01 & Valve 6 & On & FID, ECD & start sample load \\
\hline 0.01 & Valve 8 & On & FID, ECD & start sample load \\
\hline 0.02 & Valve 7 & On & FID, ECD & start sample load \\
\hline 0.50 & Valve 3 & On & FID & methaniser bypassed \\
\hline 0.50 & Valve 5 & Off & & stop signal to Labview program \\
\hline 0.55 & Aux 3 Pressure & 3.80 bar & FID & back to work pressure after Valve 3 switch \\
\hline 1.00 & Valve 8 & Off & FID, ECD & end sample injection \\
\hline 1.15 & Aux 4 Pressure & 0.15 bar & ECD & pressure adjustment according to valves position \\
\hline 1.20 & Valve 1 & On & FID & FID sample injection \\
\hline 1.20 & Valve 2 & On & ECD & ECD sample injection \\
\hline 3.30 & Valve 3 & Off & FID & sample through methaniser for $\mathrm{CO}$ detection \\
\hline 4.48 & Valve 1 & Off & FID & FID pre-column back-flushing \\
\hline 4.48 & Valve 6 & Off & FID, ECD & separate FID and ECD sample loops \\
\hline 4.50 & Aux 3 Pressure & $4.00 \mathrm{bar}$ & FID & pressure adjustment according to valves position \\
\hline 4.50 & Aux 4 Pressure & 3.00 bar & ECD & pressure adjustment according to valves position \\
\hline 4.50 & Aux 5 Pressure & $4.80 \mathrm{bar}$ & ECD & pressure adjustment according to valves position \\
\hline 4.50 & Valve 2 & Off & ECD & ECD pre-column back-flushing \\
\hline 4.50 & Valve 4 & On & ECD & lead sample to ECD, after the oxygen was flushed outside \\
\hline 4.80 & Valve 6 & On & FID, ECD & start sample load for next run \\
\hline 5.00 & Valve 8 & On & FID, ECD & start sample load for next run \\
\hline 7.00 & Aux 5 Pressure & $4.20 \mathrm{bar}$ & ECD & pressure adjustment according to valves position \\
\hline 7.00 & Valve 4 & Off & ECD & ECD bypass \\
\hline 7.00 & Valve 7 & Off & FID, ECD & MFC valve closed \\
\hline
\end{tabular}

Table A3. FID integration events.

\begin{tabular}{lll}
\hline Event & Value & Time \\
\hline Initial Slope Sensitivity & 0.900 & Initial \\
Initial Peak Width & 0.220 & Initial \\
Initial Area Reject & 1.000 & Initial \\
Initial Height Reject & 0.100 & Initial \\
Initial Shoulders & OFF & Initial \\
Integration & OFF & 0.000 \\
Integration & ON & 2.200 \\
Integration & OFF & 3.200 \\
Integration & ON & 3.450 \\
Slope Sensitivity & 0.600 & 3.500 \\
Fixed Peak Width & 0.400 & 3.500 \\
Integration & OFF & 4.450 \\
\hline
\end{tabular}

Acknowledgements. For advice regarding the setup of the Bialystok monitoring station, the authors would like to thank W. Brand, D. Worthy, R. L. Thompson, A. Vermeulen and B. B. Stephens. We thank all CHIOTTO colleagues for sharing their measurement expertise. We thank R. Leppert, J. Reith, F. Voigt, M. Rothe, M. Hielscher, and J. Seifert for important help with establishing and supporting the measurements. We thank E. D. Schulze for general support of the project. L. Sienicki and K. Katrynski provide on-going local support maintaining the system for which we are very grateful. We thank Ross Martin and Antony Gomez (NIWA) for building and installing the automated flask sampler. We are
Table A4. ECD integration events.

\begin{tabular}{lcc}
\hline Event & Value & Time \\
\hline Initial Slope Sensitivity & 0.800 & Initial \\
Initial Peak Width & 0.400 & Initial \\
Initial Area Reject & 3.915 & Initial \\
Initial Height Reject & 0.190 & Initial \\
Initial Shoulders & OFF & Initial \\
Integration & OFF & 0.000 \\
Integration & ON & 4.600 \\
Baseline Now & & 4.650 \\
Baseline Now & & 5.750 \\
Integration & OFF & 6.800 \\
\hline
\end{tabular}

grateful to TP EmiTel sp. z o.o. Poland for allowing us to install our equipment on their telecommunications tower. The Bialystok measurements were partly funded by the European Union projects, CHIOTTO (Ref. No. EVK2-CT-2002-00163) and CarboEurope IP (Ref. No. GOCE-CT-2003-505572). A. C. Manning is supported by a UK NERC/QUEST Advanced Fellowship (Ref. No. NE/C002504/1).

The service charges for this open access publication have been covered by the Max Planck Society.

Edited by: S. Reimann 


\section{References}

Bakwin, P. S. and Tans, P. P.: Measurements of carbon dioxide on a very tall tower, Tellus, 47B, 535-549, 1995.

Bakwin, P. S., Tans, P. P., Hurst, D. F., and Zhao, C.: Measurements of carbon dioxide on very tall towers: results of the NOAA/CMDL program, Tellus, 50B, 401-415, 1998.

Broecker, W. S. and Peng, T.-H.: Tracers in the Sea, LamontDoherty Geological Observatory, Palisades, N.Y., 1982.

Dlugokencky, E. J., Bruhwiler, L., White, J. W. C., Emmons, L. K., Novelli, P. C., Montzka, S. A., Masarie, K. A., Lang, P. M., Crotwell, A. M., Miller, J. B., and Gatti, L. V.: Observational constraints on recent increases in the atmospheric $\mathrm{CH}_{4}$ burden, Geophys. Res. Lett., 36, L18803, doi:10.1029/2009GL039780, 2009.

Fan, S., Gloor, M., Mahlman, J., Pacala, S., Sarmiento, J., Takahashi, T., and Tans, P.: A Large Terrestrial Carbon Sink in North America Implied by Atmospheric and Oceanic Carbon Dioxide Data and Models, Science, 282, 442-446, doi:10.1126/science.282.5388.442, 1998.

Gamnitzer, U., Karstens, U., Kromer, B., Neubert, R. E. M., Meijer, H. A. J., Schroeder, H., and Levin, I.: Carbon monoxide: A quantitative tracer for fossil fuel CO2?, J. Geophys. Res., 111, D22302, doi:10.1029/2005JD006966, 2006.

Gloor, M., Fan, S., Pacala, S., and Sarmiento, J.: Optimal sampling of the atmosphere for purpose of inverse modeling: A model study, Global Biogeochem. Cy., 14, 407-428, 2000.

Gloor, M., Bakwin, P., Hurst, D., Lock, L., Draxler, R., and Tans, P. P.: What is the concentration footprint of a tall tower?, J. Geophys. Res., 106, 17831-17840, 2001.

Haszpra, L., Barcza, Z., Bakwin, P. S., Berger, B. W., Davis, K. J., and Weidinger, T.: Measuring system for the long-term monitoring of biosphere/atmosphere exchange of carbon dioxide, J. Geophys. Res., 106, 3057-3070, 2001.

Haszpra, L., Barcza, Z., Hidy, D., Szilágyi, I., Dlugokencky, E., and Tans, P.: Trends and temporal variations of major greenhouse gases at a rural site in Central Europe, Atmos. Environ., 42, 8707-8716, 2008.

Henne, S., Brunner, D., Folini, D., Solberg, S., Klausen, J., and Buchmann, B.: Assessment of parameters describing representativeness of air quality in-situ measurement sites, Atmos. Chem. Phys. Discuss., 9, 20019-20062, 2009,

http://www.atmos-chem-phys-discuss.net/9/20019/2009/.

Hurst, D. F., Bakwin, P. S., Myers, R. C., and Elkins, J. W.: Behavior of trace gas mixing ratios on a very tall tower in North Carolina, J. Geophys. Res., 102(D7), 8825-8835, 1997.

Inoue, $\mathrm{H}$. Y. and Matsueda, $\mathrm{H}$.: Measurements of atmospheric $\mathrm{CO}_{2}$ from a meteorological tower in Tsukuba, Japan, Tellus B, 53, 205-219, 2001.

Jiang, X., Ku, W. L., Shia, R.-L., Li, Q., Elkins, J. W., Prinn, R. G., and Yung, Y. L.: Seasonal cycle of $\mathrm{N}_{2} \mathrm{O}$ : Analysis of data, Global Biogeochem. Cy., 21, GB1006, doi:10.1029/2006GB002691, 2007.

Jordan, A., Schultz, U., Seifert, T., Gloor, M., Manning, A., Heimann M., and Schulze, E.-D.: Continuous GC measurements of trace gases at the Ochsenkopf monitoring station, in: WMOGAW Report 161, Proceedings of the 12th IAEA/WMO meeting of $\mathrm{CO}_{2}$ experts, Toronto, 2003, 2005.
Keeling, R. F.: Development of an interferometric oxygen analyzer for precise measurement of the atmospheric $\mathrm{O}_{2}$ mole fraction, Harvard University, Cambridge, Massachusetts, USA, 178 pp., 1988.

Keeling, R. F. and Shertz, S. R.: Seasonal and interannual variations in atmospheric oxygen and implications for the global carbon cycle, Nature, 358, 723-727, doi:710.1038/358723a358720, 1992.

Keeling, R. F., Manning, A., McEvoy, E. M., and Shertz, S. R.: Methods for measuring changes in atmospheric $\mathrm{O}_{2}$ concentration and their application in southern hemisphere air, J. Geophys. Res., 103, 3381-3307, 1998a.

Keeling, R. F., Stephens, B. B., Najjar, R. G., Doney, S. C., Archer, D., and Heimann, M.: Seasonal Variations in the Atmospheric O2/N-2 Ratio in Relation to the Kinetics of Air-Sea Gas Exchange, Global Biogeochem. Cy., 12, 141-163, 1998b.

Keeling, R. F., Manning, A. C., Paplawsky, W. J., and Cox, A. C.: On the long-term stability of reference gases for atmospheric $\mathrm{O}_{2} / \mathrm{N}_{2}$ and $\mathrm{CO}_{2}$ measurements, Tellus, 59B, 3-14, 2007.

Kozlova, E. A. and Manning, A. C.: Methodology and calibration for continuous measurements of biogeochemical trace gas and $\mathrm{O}_{2}$ concentrations from a 300-m tall tower in central Siberia, Atmos. Meas. Tech., 2, 205-220, 2009, http://www.atmos-meas-tech.net/2/205/2009/.

Kozlova, E. A., Manning, A. C., Kisilyakhov, Y., Seifert, T., and Heimann, M.: Seasonal, synoptic, and diurnal-scale variability of biogeochemical trace gases and $\mathrm{O}_{2}$ from a 300-m tall tower in central Siberia, Global Biogeochem. Cy., 22, GB4020, doi:10.1029/2008GB003209, 2008.

Levin, I., Ciais, P., Langenfelds, R., Schmidt, M., Ramonet, M., Sidorov, K., Tchebakova, N., Gloor, M., Heimann, M., Schultze, E. D., Vygodskaya, N. N., Shibistova, O., and Lloyd, J.: Three years of trace gas observations over the EuroSiberian domain derived from aircraft sampling - A concerted action, Tellus B, 54, 696-712, 2002.

Lundin, L. C., Cienciala, E., Grelle, A., Halldin, S., Hjelm, P., Kellner, E., Lindroth, A., Lundberg, A., Morén, A. S., Nord, T., Seibert, J., and Staehli, M.: Continuous long-term measurements of soil-plant-atmosphere variables at a forest site, Agr. Forest Meteorol., 98-9 (Special Issue SI), 53-73, 1999.

Manning, A. C., Jordan, A., Levin, I., Schmidt, M., Neubert, R. E. M., Etchells, A., Steinberg, B., Ciais, P., Aalto, T., Apadula, F., Brand, W. A., Delmotte, M., Giorgio di Sarra, A., Hall, B., Haszpra, L., Huang, L., Kitzis, D., van der Laan, S., Langenfelds, R. L., Leuenberger, M., Lindroth, A., Machida, T., Meinhardt, F., Moncrieff, J., Morguí, J. A., Necki, J., Patecki, M., Popa, E., Ries, L., Rozanski, K., Santaguida, R., Steele, L. P., Strom, J., Tohjima, Y., Thompson, R. L., Vermeulen, A., Vogel, F., and Worthy, D.: Final report on CarboEurope "Cucumber" intercomparison programme, 1-23, available at: http://cucumbers.webapp2.uea.ac. uk/documents/CucumberFinalReport_Final.pdf, last access: 30 January 2010, 2009.

Manning, A. C.: Temporal variability of atmospheric oxygen from both continuous measurements and a flask sampling network: Tools for studying the global carbon cycle, Ph.D. thesis, University of California, San Diego, 2001. 
Manning, A. C. and Keeling, R. F.: Global oceanic and land biotic carbon sinks from the Scripps atmospheric oxygen flask sampling network, Tellus B, 58B, 95-116, doi:110.1111/j.16000889.2006.00175.x, 2006.

Nevison, C. D., Lueker, T. J., andWeiss, R. F.: Quantifying the nitrous oxide source from coastal upwelling, Global Biogeochem. Cy., 18, GB1018, doi:10.1029/2003GB002110, 2004.

Popa, M. E.: Continuous tall tower multi-species measurements in Europe for quantifying and understanding land-atmosphere carbon exchange, $\mathrm{PhD}$. thesis, Friedrich Schiller University, Jena, 2008, available at: http://www.db-thueringen.de/ servlets/DerivateServlet/Derivate-14971/Popa/Dissertation.pdf, http://www.bgc-jena.mpg.de/bgc-systems/dissertations/ Popa_thesis.pdf, last access: 1 December 2009, 2008.

Prentice, I. C., Heimann, M., and Sitch, S.: The carbon balance of the terrestrial biosphere: ecosystem models and atmospheric observations, Ecol. Appl., 10, 1553-1573, doi:10.1890/10510761(2000)010[1553:TCBOTT]2.0.CO;2, 2000.

Schimel, D. S., House, J. I., Hibbard, K. A., Bousquet, P., Ciais, P., Peylin, P., Braswell, B. H., Apps, M. J., Baker, D., Bondeau, A., Canadell, J., Churkina, G., Cramer, W., Denning, A. S., Field, C. B., Friedlingstein, P., Goodale, C., Heimann, M., Houghton, R. A., Melillo, J. M., Moore, B., Murdiyarso, D., Noble, I., Pacala, S. W., Prentice, I. C., Raupach, M. R., Rayner, P. J., Scholes, R. J., Steffen, W. L., and Wirth, C.: Recent patterns and mechanisms of carbon exchange by terrestrial ecosystems, Nature, 414 , 169-172, 2001.

Severinghaus, J. P.: Studies of the terrestrial $\mathrm{O}_{2}$ and carbon cycles in sand dune gases and in Biosphere 2, Ph.D. thesis, Columbia University, Palisades, NY, 148 pp., 1995.

Sirignano, C., Neubert, R. E. M., Rdenbeck, C., and Meijer, H. A. J.: Atmospheric oxygen and carbon dioxide observations from two European coastal stations 2000-2005: continental influence, trend changes and APO climatology, Atmos. Chem. Phys., 10, 1599-1615, 2010, http://www.atmos-chem-phys.net/10/1599/2010/.

Stephens, B. B., Keeling, R. F., Heimann, M., Six, K. D., Murnane, R., and Caldeira, K.: Testing global ocean carbon cycle models using measurements of atmospheric $\mathrm{O}_{2}$ and $\mathrm{CO}_{2}$ concentration, Global Biogeochem. Cy., 12, 213-230, 1998.

Stephens, B. B., Bakwin, P., Tans, P., and Teclaw, R.M.: Measurements of atmospheric $\mathrm{O}_{2}$ variations at the WLEF tall-tower site, Sixth International Carbon Dioxide Conference, Extended Abstracts, Sendai, Japan, 2001, 78-80, 2001.
Stephens, B. B., Bawkin, P., Tans, P. P., Teclaw, R., and Baumann, D.: Application of a differential fuel-cell analyzer for measuring atmospheric oxygen variations, J. Atmos. Ocean. Tech., 24(1), 82-94, doi:10.1175/JTECH1959.1, 2007.

Sturm, P., Leuenberger, M., Moncrieff, J., and Ramonet, M.: Atmospheric $\mathrm{O}^{2}, \mathrm{CO}^{2}$ and ${ }^{13} \mathrm{C}$ measurements from aircraft sampling over Griffin Forest, Perthshire, UK, Rapid Commun. Mass Sp., 19, 2399-2406, 2005.

Sturm, P., Leuenberger, M., and Valentino, F. L.: On thermal fractionation effects at air intakes, in: WMO-GAW Report 168, 13th WMO/IAEA Meeting of Experts on Carbon Dioxide Concentration and Related Tracers Measurement Techniques, Boulder, Colorado, US, 2005, 106-109, 2006.

Tans, P. P.: Uncertainties in the Global Carbon Cycle, Pure Appl. Chem., 63, 766-768, 1991.

Thompson, R. L., Manning, A. C., Gloor, E., Schultz, U., Seifert, T., Hänsel, F., Jordan, A., and Heimann, M.: In-situ measurements of oxygen, carbon monoxide and greenhouse gases from Ochsenkopf tall tower in Germany, Atmos. Meas. Tech., 2, 573591, 2009, http://www.atmos-meas-tech.net/2/573/2009/.

Vermeulen, A. T., Eisma, R., Hensen, A., and Slanina, J.: Transport model calculations of NW-European methane emissions, Environ. Sci. Policy, 2, 315-324, 1999.

Vermeulen, A. T., Hensen, A., den Ouden, A. C. B., and Pieterse, G.: Validation of methane emission inventories for NW Europe, ECN, Petten, Report ECN-C-96-088, available at: http://www. ecn.nl/docs/library/report/1996/c96088.pdf, last access: 30 January 2010, 1997.

Vermeulen, A. T., Hensen, A., Gloor, M., Manning, A. C., Ciais, P., Eisma, R., van den Bulk, W. C. M., Mols, J. J., and Erisman, J. W.: CHIOTTO - Continuous High-Precision Tall Tower Observations of Greenhouse Gases, JRC, Ispra, available at: http://ccu.jrc.ec.europa.eu/Pubblications/IM_WS_report final_V2.pdf, 2004.

WMO: GAW 161: 12th WMO/IAEA Meeting of Expert on Carbon Dioxide Concentration and Related Tracers Measurements Techniques (Toronto, Canada, 15-18 September 2003), 2005.

WMO: WMO Greenhouse Gas Bulletin No. 4, 1-4, 2008.

WMO: WMO Greenhouse Gas Bulletin No. 5, 1-4, 2009.

Worthy, D. E., Platt, J. A., Kessler, R., Ernst, M., and Racki, S.: The Greenhouse Gases Measurement Program, Measurement Procedures and Data Quality, Meteorological Service of Canada, 97120, 2003. 